\title{
Hardening slip model for reinforcing steel bars
}

\author{
Franco Braga ${ }^{1}$, Silvia Caprili ${ }^{* 2}$, Rosario Gigliotti ${ }^{1}$ and Walter Salvatore ${ }^{2}$ \\ ${ }^{1}$ Department of Structural Engineering and Geotechnics, University of Rome "La Sapienza", \\ via Eudossiana 18, 00184, Rome, Italy \\ ${ }^{2}$ Department of Civil and Industrial Engineering, University of Pisa, Largo Lucio Lazzarino 1 , \\ 56122, Pisa, Italy
}

(Received July 4, 2014, Revised March 22, 2015, Accepted April 2, 2015)

\begin{abstract}
A new constitutive model for the representation of the seismic behaviour of steel bars including hardening phenomena is presented. The model takes into account relative slip between bars and concrete, necessary for the estimation of the structural behaviour of r.c. elements and of the level of strain induced by earthquakes on bars. The present work provides the analytical formulation of the post-yielding behaviour of reinforcements, resulting in a continuous axial stress-slip relationship to be implemented in engineering software. The efficacy of the model is proved through the application to a cantilever column, for whose bars the constitutive law is derived.
\end{abstract}

Keywords: relative slip; hardening effects; cyclic behavior; stress-slip relationship; reinforcing bars

\section{Introduction}

Several works were provided in the past literature dealing with the representation of the behaviour of reinforced concrete (r.c.) elements or sub-structures through the use of numerical models and constitutive laws elaborated to reproduce the monotonic and cyclic properties of materials and structures. The results presented by Hakuto et al. (1999), Gigliotti (2002), Braga et al. (2012) evidenced the inadequacy of neglecting the relative slip between longitudinal reinforcing bars and surrounding concrete, causing the improper evaluation of the cyclic behaviour of the structure. The numerical models characterized by the assumption of perfect-bond between bars and concrete (Menegotto and Pinto 1973, Mander et al. 1984 and others) often provide results not in agreement with the ones coming from experimental tests on r.c. sub-structures or elements, as widely presented by D'Amato et al. (2012), Limkatanyu and Spacone (2008), Braga et al. (2012). The influence of relative slip was evidenced both in the case of plain steel reinforcements, i.e., existing r.c. buildings characterized by poor structural details (Ciampi et al. 1983, D'Amato et al. 2012) and in the case of ribbed bars. The inadequacy of structural detailing and the following degradation of bond strength caused an insufficient structural available ductility in presence of cyclic loads, evidencing the fundamental role of bond slip phenomena in the response of r.c. structures (Hakuto et al. 1999). The experimental tests executed by Bertero and Popov (1977)

*Corresponding author, Ph.D., E-mail: silvia.caprili@ing.unipi.it 
highlighted the possibility of neglecting relative slip until yielding, underlining at the same time the inconsistencies of the results for increasing levels of the applied force, when the generation of uniaxial stresses and strains on the bar led to the cracking of the concrete, to the breaking of the bond between bar and concrete and to the relative final displacement between the reinforcement and the adjacent concrete.

Many works were proposed regarding the elaboration of models able to represent the influence of relative slip between steel bars and concrete on the behaviour of r.c. structures, often resulting in very complex systems not applicable to the engineering practice of buildings' analysis and design but, at most, to single structural elements. Ngo and Scordelis (1969) proposed a linear elastic finite element model of a simply supported steel-concrete beam made up of constant strain triangular elements with concentrated bond link connections modeled through orthogonal dimensionless springs. Keuser and Mehlhorn (1987) introduced a contact element providing continuity between steel and concrete and Rubiano-Benavides (1998) proposed a model with rotational springs at the ends of the elements for reproducing the additional flexibility due to bond-slip phenomena. Monti et al. (1993) analyzed the problem of a bar embedded in the concrete for a certain length, determining the trends of axial stress, axial strain, bond stress and slip along the reinforcement solving the problem through the use of equilibrium, compatibility and constitutive equations. Fabbrocino et al. (2004) elaborated a model for the anchorage of plain bars in existing r.c. buildings determining the force transfer mechanism governing the behaviour of the reinforcing bar in tension. Vecchio and Collins (1986) elaborated a general model for two-dimensional cracked r.c. elements representing the cracked concrete with a specific stress-strain behaviour directly taking into account the effects of local strains at cracks, strains between cracks, bond-slip, and crack slip.

All the models herein presented, validated through experimental tests, did not provide information about the effects of relative slip on the stress-strain behaviour of reinforcing bars under monotonic and cyclic loads, topic that consequently shall be deeply investigated. In the current engineering practice, perfect-bond constitutive laws are generally used to represent the monotonic and cyclic behaviour of steel reinforcements. Such laws usually do not include the effects of relative slip bar/concrete, leading to an improper evaluation of stresses and strains due to external loading conditions on r.c. structures. Looking at constitutive laws for reinforcements, for instance, the Menegotto-Pinto (1973) law correctly reproduces the transition from the elastic to the plastic range including the Baushinger effect but neglecting relative slip. Mander et al. (1984) provided a constitutive law including strain-hardening phenomena while Monti and Nuti (1992) elaborated a model calibrated on the base of experimental tests on different samples considering or neglecting buckling phenomena and introducing different hardening rules.

Other models were also provided (Dodd and Restrepo Posada 1995, Gomes and Appleton 1997), mainly referred to single bare bar, without taking into consideration the interaction with surrounding concrete (Menegotto and Pinto 1973, Mander et al. 1984) or introducing a very complex modelling of relative slip (Monti et al. 1993, Monti and Nuti 1992, Lowes and Altoontash 2003), usually not easy to be applied for the analysis of modern r.c. buildings. More recently, Braga et al. (2012) elaborated a simple model including relative slip between steel and concrete and providing the axial stress-slip relationship through the adoption of simple equilibrium, compatibility and constitutive equations. Starting from the results of experimental tests on r.c. beam to column sub-assemblages (Gigliotti 2002) and highlighting the importance of relative slip mainly in presence of an inadequate anchorage length, the slip model allowed to directly include relative slip in the numerical simulations also for very complex buildings with a reduced computational effort. The results provided by the adoption of the slip model (Braga et al. 2012, 
D'Amato et al. 2012) were in good agreement, at a global force-displacement level, with the ones coming from experimental tests on r.c. elements and sub-structures; anyway, despite its simple application and development, the slip model (Braga et al. 2012) was based on the strong simplification of the elasto-plastic constitutive law for steel bars, not properly representative of the strain condition of reinforcements under cyclic/seismic loads.

As a consequence, an improvement to the slip model proposed by Braga et al. (2012) has been developed and is hereafter presented. The hardening slip model can be adopted for the representation of the cyclic/seismic behaviour of steel bars in r.c. structures, in which plastic deformation can be determined. The model was developed as a part of the European research project RUSTEEL, Effects of Corrosion on Low-Cycle Fatigue (Seismic) Behaviour of High Strength Steel Reinforcing Bars (2009-2012), whose main aims consisted in the investigation of the behaviour of reinforcing bars under the combined effects of cyclic action and corrosion phenomena (Braconi et al. 2012, Braconi et al. 2013, Braconi et al. 2014, Caprili and Salvatore 2014). Actual design codes for r.c. buildings (EN 1998-1:2005; D.M. 14/01/2008) prescribe the development of high plastic deformations in specific regions of structural elements to obtain a global dissipative collapse mechanism. The ductile behaviour of r.c. structures depends on the cyclic capacity of bars located in those areas where plastic deformations are expected: steel reinforcements are subjected to few cycles of high plastic deformations (Teran-Gilmore and Jirsa, 2007) and in order to understand the cyclic behaviour of steel bars, a model including relative slip and hardening phenomena is then necessary. The hardening slip model aims to overcome the limits related to the model proposed by Braga et al. (2012) due to the simplification of an elasto-plastic relationship for steel, allowing the determination of the values of axial stress, slip and strain due to cyclic loads on reinforcing bars in r.c. structures, often subjected to high plastic deformations.

\section{Basic hypotheses and proposed model}

\subsection{Main assumptions at the base of the model}

The hardening slip model describes the behaviour of steel bars in r.c. structures including relative slip and hardening phenomena, in order to represent the stress-strain condition due to cyclic/seismic action in both r.c. elements and reinforcements. Simplified assumptions are adopted for the formulation of the model for what concerns the slip field along the bar, the bond stress-slip relationship and the constitutive axial stress-strain law describing the behaviour of steel bars (Fig. 1); in particular:

- the slip field $u(x)$ is assumed bi-linear along the bar, with two different branches respectively

representing the condition before and after the yielding point;

- the bond stress-slip relationship is assumed elastic-perfectly plastic;

- the stress-strain constitutive law for steel is assumed elastic-plastic with hardening;

- the anchorage at the bar end is represented as a linear function of the displacement $u_{0}$.

The slip field $u(x)$ along the bar is characterized by a bi-linear behaviour: this point constitutes the stronger simplification in the analytical formulation of the constitutive axial stress-slip relationship. Anyway, according to what presented by D'Amato et al. (2012), the linear schematization of the slip field already adopted by Braga et al. (2012) does not lead to relevant differences with respect to the results obtained by the adoption of refined models such as, for instance, the one proposed by Monti et al. (1997). A more detailed justification of the assumption 


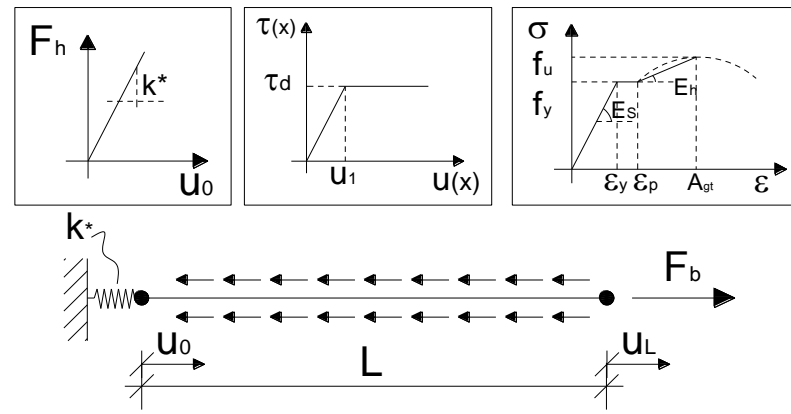

Fig. 1 Simplifications assumed for the hardening slip model

was provided by D'Amato et al. (2012): the good agreement in terms of relative slip of the results coming from the two models was evidenced in the case of more than 50 simulations for different bar's diameter, different values of yielding strength and bond stress considering both the cases of bar pull-out and bar yielding. In the present work, based on the linearization of slip already explained and in order to represent the increase of relative slip due to the hardening phenomena, two different linear branches are determined, describing the behaviour before and after the overcoming of the yielding strength. The slip field $u(x)$ along the bar before yielding is then defined by Eq. (1)

$$
u(x)=\bar{u}_{0}+\frac{x}{L_{0}}\left(u_{L}-\bar{u}_{0}\right)
$$

being

$$
\bar{u}_{0}= \begin{cases}0 & L_{0}<L \\ u_{0} & L_{0}=L\end{cases}
$$

in which $u_{0}$ and $u_{L}$ represent the bar's end displacements, $x$ is the generic abscissa along the bar and $L_{0}$ the portion of the bar involved in relative slip. Fig. 2 shows the trends of axial slip and axial stress along the bar before yielding in the two above presented conditions.

After yielding, the increase of axial stress due to hardening phenomena leads to the corresponding increase of relative slip; the trend of axial slip along the bar is then approximated by two different branches, as presented by Eq.(3), in which $\bar{u}_{0}$ is defined according to Eq.(2) and $L_{y}$

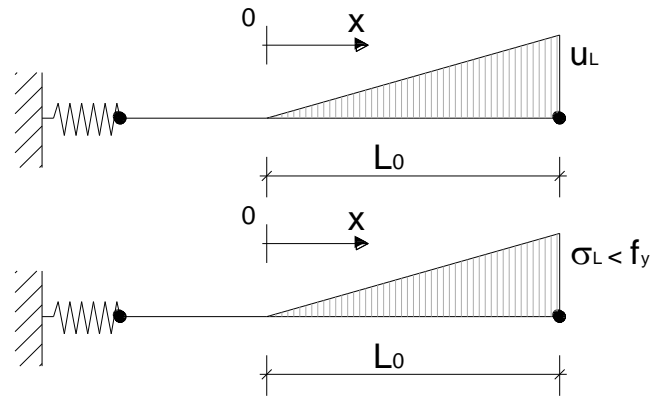

(a)

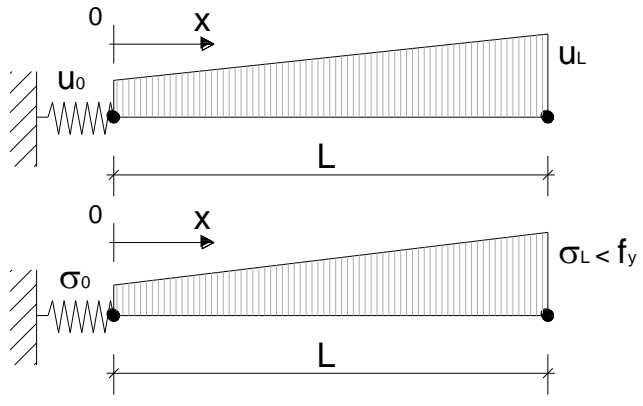

(b)

Fig. 2 Axial slip and axial stress along the bar before yielding: (a) $u_{0}=0-L_{0}<L$, (b) $u_{0} \neq 0-L_{0}=L$ 
is the part of the bar in which $u(x) \geq u_{y}, u_{y}$ being the value of displacement corresponding to the yielding strength $f_{y}$ (Fig. 3). If the axial stress increases, the part of the bar involved in the postyielding phenomena increases following the trend of $L_{y}$

$$
u(x)= \begin{cases}\bar{u}_{0}+\frac{u_{y}-\bar{u}_{0}}{L_{0}-L_{y}} \cdot x & \text { for } 0 \leq \mathrm{x} \leq \mathrm{L}_{0}-\mathrm{L}_{\mathrm{y}} \\ u_{y}+\frac{u_{L}-u_{y}}{L_{y}} \cdot\left(x-L_{0}+L_{y}\right) & \text { for } \mathrm{L}_{0}-\mathrm{L}_{\mathrm{y}}<\mathrm{x} \leq \mathrm{L}_{0}\end{cases}
$$

The bond stress-slip law, in agreement with the slip model (Braga et al. 2012, Gigliotti 2002), is schematized elastic-perfectly plastic, following the approach assumed by Verderame et al. (2001) and adopting the values proposed by Model Code (CEB-FIP 1993) for generic bond condition. The bond stress-slip field is consequently described by Eq. (4)

$$
\tau(x)= \begin{cases}\frac{\tau_{d}}{u_{1}} \cdot u(x) & \text { if } \mathrm{u}(\mathrm{x}) \leq \mathrm{u}_{1} \\ \tau_{d} & \text { if } \mathrm{u}(\mathrm{x})>\mathrm{u}_{1}\end{cases}
$$

in which $u(x)$ represents the axial slip field along the bar (Figs. 2-3), $\tau_{d}$ is the residual value of bond stress and $u_{1}$ the corresponding slip.

The hypotheses used for the formulation of bond stress-slip relationship, already adopted by Braga et al. (2012) for the slip model "base" of the hardening slip one, come from the results of the experimental beam tests with plain bars executed by Verderame et al. (2001), evidencing a bond stress-slip behaviour characterized by a peak followed by a rapid decrease up to a residual value of the bond stress (Fig. 4). As a consequence, an elastic-perfectly plastic model for bond-slip relationship is adopted, neglecting the degrading branch of the constitutive relationship and taking into account the residual value of the bond stress $\left(\tau_{d}\right)$. For what concerns the values to assume for the mechanical characterization of the bond stress-slip field $\left(\tau_{d}, u_{1}\right)$, Ciampi et al. (1983) evidenced that reversed cycling action caused a progressive degradation of bond resistance and consistent pinching phenomena on r.c. structures, mainly related to the development of shear cracks in concrete between two consecutive ribs; as a consequence, the envelope curve describing the monotonic behaviour of the bond stress-slip relationship was generally reduced for considering the effects of the cyclic loading action. The reduction factors were strongly dependent on the total dissipated energy, the amplitude of slip, the number of cycles executed and the confinement rate. In order to consider the progressive degradation due to cyclic action in new constructions, generally characterized by an initial perfect bond, in the bilinear schematization of the bond stressslip relationship the residual value of bond stress corresponding to the behaviour of confined concrete with "generic bond condition" (CEB-FIP 1993) is adopted ( $\left.\tau_{f}=\tau_{d}\right)$ (Fig. 5(a)).

For the stress-strain relationship of steel reinforcing bars, an elastic-plastic with hardening law is considered (Fig. 5(b)): the hardening branch is schematized with a linear behaviour up to the point in which the maximum load is reached. The hardening modulus is so defined by Eq. (5)

$$
E_{h}=\frac{f_{u}-f_{y}}{A_{g t}-\varepsilon_{p}}
$$

in which $f_{u}$ and $f_{y}$ represent the ultimate and yielding strength, $\varepsilon_{p}$ the total deformation at the beginning of the hardening branch and $A_{g t}$ the deformation corresponding to maximum load. 

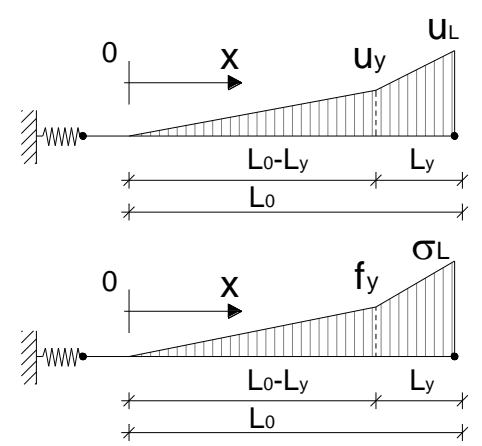

(a)
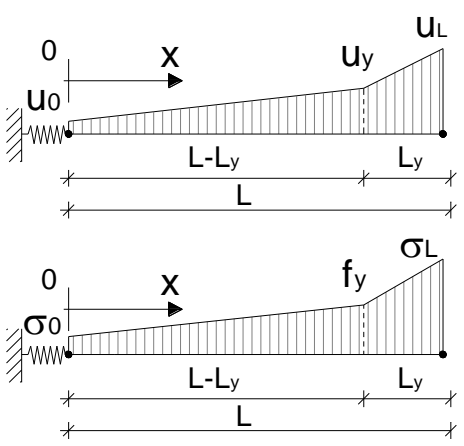

(b)

Fig. 3 Axial slip and axial stress along the rebar after yielding: (a) $u_{0}=0-L_{0}<L$, (b) $u_{0} \neq 0-L_{0}=L$

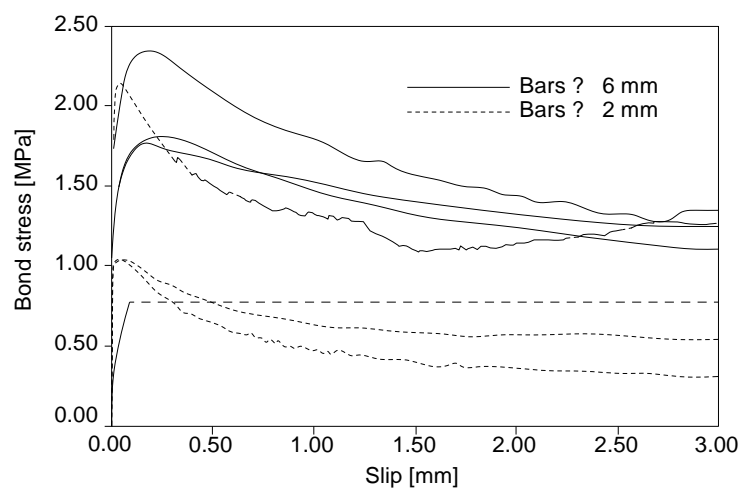

Fig. 4 Results of experimental beam tests with different plain rebars (Verderame et al. 2001)

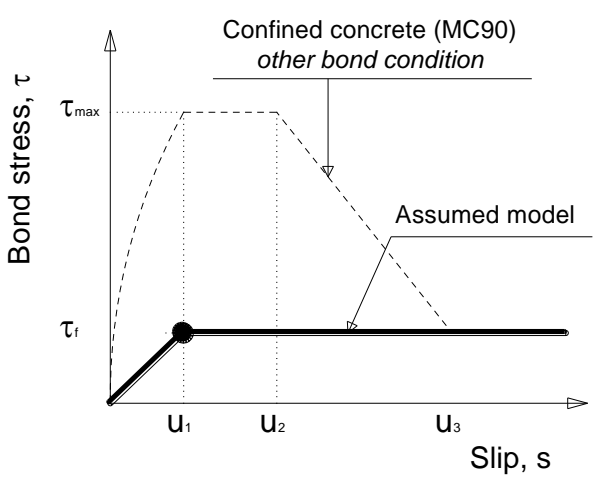

(a)

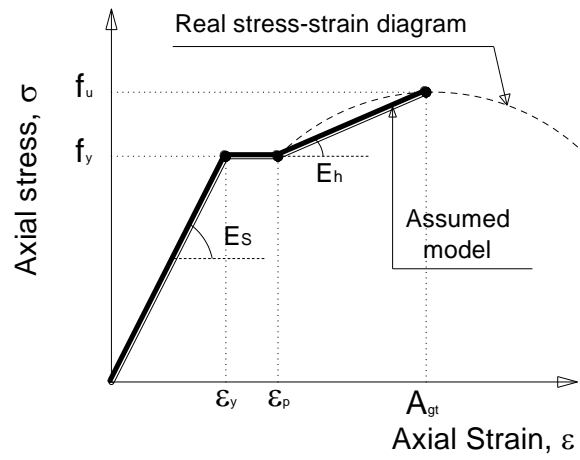

(b)

Fig. 5 (a) Simplified scheme adopted for the bond stress-slip constitutive law for ribbed bars, (b) Simplified scheme adopted for the axial stress-strain constitutive law for ribbed bars

The anchorage of the bar, if present, is represented as a linear function of the displacement corresponding to the end $\left(\bar{u}_{0}\right)$, according to Eq. (6), in which $k_{h}$ represents the hook stiffness, opportunely determined in relation to the characteristics of the anchorage. 


$$
F_{h}=k_{h} \cdot \bar{u}_{0}
$$

It's necessary to underline that all the previous assumptions constitute simplifications of the non linear bond-slip phenomena, necessary to describe the process without the necessity of an iterative procedure or an heavy computational effort and consequently useful for practical engineering purposes (Braga et al. 2012).

\subsection{Numerical formulation of the proposed model}

On the basis of the aforementioned hypotheses, the problem herein presented can be solved in a simple closed form through the use of equilibrium, compatibility and constitutive equations, allowing the determination of a continuous axial stress-slip relationship for the bar.

Starting from the formulation of the slip field, expressed by Eqs. (1), (2) and (3) in relation to the specific conditions of the considered specimen (i.e., before or after the achievement of yielding strength), and of the bond stress-slip relation provided by Eq. (4), the equilibrium equation expressed by Eq. (7)

$$
\sigma(x)=\frac{F(x)}{A_{b}}=\frac{1}{A_{b}} \int_{0}^{x} \tau(z) \pi D d z+\frac{F_{h}}{A_{b}}
$$

allows the determination of the axial stress field along the bar of diameter $D$ and transversal area $A_{b} . F_{h}$ represents the force acting in correspondence of the hooked end, described by Eq. (6).

The use of the compatibility relationships introducing the constitutive equations provides the formulation of relative slip between the two ends of the bar before and after yielding (Eqs. (8)-(9), respectively). As visible from Eq. (9), the two different contributions related to relative slip corresponding to axial stresses lower and higher than yielding are considered, assuming the hardening relationship over a length equal to $L_{y}$, for which $\sigma(x) \geq f_{y}$. The increase of deformation during the phase in which the yielding strength remains constant (i.e., plateau) is taken into consideration introducing the increment of strain equal to $\varepsilon_{p}$ in the definition of the displacement/relative slip, creating the connection between the end of the elastic range $\left(\varepsilon_{y}-f_{y}\right)$ and the beginning of the hardening branch $\left(\varepsilon_{p}-f_{y}\right)$.

$$
\begin{array}{cc}
\Delta u=u_{L}-u_{0}=\int_{0}^{L} \frac{\sigma(x)}{E_{s}} d x=u_{E}(L) & \sigma(x) \leq f_{y} \\
\Delta u=u_{L}-u_{0}=\int_{0}^{L-L_{y}} \frac{\sigma(x)}{E_{s}} d x+\int_{L-L_{y}}^{L} \varepsilon_{p}+\frac{\sigma(x)-f_{y}}{E_{h}} d x & \sigma(x)>f_{y}
\end{array}
$$

In the post-yielding condition, taking into account the equilibrium condition along the bar, the portion of the bar in which $u(x) \geq u_{y}$ (that is $\sigma(x) \geq f_{y}$ ) can be easily determined (Fig. 6) according to Eq. (10)

$$
\int_{L_{0}-L_{y}}^{L_{0}} \pi D \tau(x) d x=\frac{\pi D^{2}}{4} \cdot\left(\sigma\left(L_{0}\right)-f_{y}\right)
$$




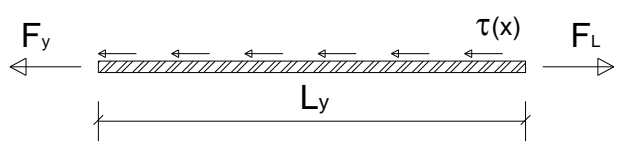

Fig. 6 Equilibrium condition for the bar

More in details, the formulation of the axial stress-slip relationship of the bar follows exactly the analytical equations provided by Braga et al. (2012) until the achievement of the yielding strength in correspondence of the free end of the specimen. For the analytical equations describing the problem in the case of $u(x) \geq u_{y}$, different cases can be determined in relation to the length of the bar directly influenced by relative slip; in particular, as well as in the slip model presented in the current scientific literature (Braga et al. 2012), two main situations are determined, considering an involved length respectively lower or equal to the total length of the bar.

The general procedure for the definition of the continuous axial stress-slip relationship is briefly herein summarized, pointing out the main steps adopted in the formulation.

The slip field is defined by two different branches, before and after yielding; the general formulation, coming from Eqs. (1), (2) and (3), turns then into Eq. (11) for the case $L_{0} \leq L$ and into Eq. (12) in the other cases

$$
\begin{gathered}
u(x)= \begin{cases}\frac{u_{y}}{L_{0}-L_{y}} \cdot x & \text { if } 0 \leq \mathrm{x} \leq \mathrm{L}_{0}-\mathrm{L}_{\mathrm{y}} \\
u_{y}+\frac{u_{L}-u_{y}}{L_{y}} \cdot\left(x-L_{0}+L_{y}\right) & \text { if } \mathrm{L}_{0}-\mathrm{L}_{\mathrm{y}}<\mathrm{x} \leq \mathrm{L}_{0}\end{cases} \\
u(x)= \begin{cases}u_{0}+\frac{u_{y}-u_{0}}{L-L_{y}} \cdot x & \text { if } 0 \leq \mathrm{x} \leq \mathrm{L}-\mathrm{L}_{\mathrm{y}} \\
u_{y}+\frac{u_{L}-u_{y}}{L_{y}} \cdot\left(x-L+L_{y}\right) & \text { if } \mathrm{L}-\mathrm{L}_{\mathrm{y}}<\mathrm{x} \leq \mathrm{L}\end{cases}
\end{gathered}
$$

About this point, some additional remarks shall be made: in the case of plain smooth bars $u_{l}$ is usually equal to $0.10 \mathrm{~mm}$ (CEB-FIP 1993), usually lower than the $u_{y}$ and consequently leading to neglect the condition $u_{1} \geq u_{L} \geq u_{y}$. For ribbed bars, on the other hand, the values assumed for $u_{1}$ can vary between $0.40 \mathrm{~mm}$ to $1.0 \mathrm{~mm}$, and consequently the value of the slip corresponding to yielding can be even lower than $u_{1}$ : this increases the number of conditions that shall be taken into consideration in the whole formulation of the hardening slip model. The bond stress field along the bar can be then characterized by two or three different branches defined as a function of the associated slip: the general formulation for bond stress provided by Eq. (4) turns into two of three branches, as deeply presented in the Appendix to the paper.

The application of equilibrium condition (Eq. (7)) finally allows the determination of the axial stress field along the bar, while the use of compatibility equation (Eq. (9)) provides the formulation of relative slip between the two ends of the bar, considering the elastic constitutive law until yielding and integrating the hardening strain field over a length equal to $L_{y}$. 


\section{Analytical solution}

The problem of the a steel bar embedded in a concrete block is solved considering the progressive increase of the axial stress and evaluating the corresponding increase of the axial slip, leading to a continuous axial stress-slip relationship describing the behaviour of the bar. In this framework, different cases shall be then distinguished depending on the value of $L_{0}$ (i.e., the part of the total length of the bar involved in relative slip) in comparison with the total length of the reinforcement $(L)$. Considering that the value of $L_{0}$ increases with the value of the axial stress, the following Cases, indicated with the letters A, B, C and D, are then possible:

- Cases A - $L_{0}$ is always lower than $L$ (before yielding, after yielding and until rupture);

- Cases B - $L_{0}$ is always equal to $L$ (before yielding, after yielding and until rupture);

- Cases $\mathrm{C}-L_{0}$ is lower than $L$. With the increase of the axial stress, $L_{0}$ reaches $L$ before yielding.

- Cases D - $L_{0}$ is lower than $L$. With the increase of the axial stress, $L_{0}$ reaches $L$ after yielding.

In each considered Case (A, B, C or D) the following conditions shall be distinguished:

1. $u_{1}>u_{L}>u_{y}$

2. $u_{L}>u_{1}>u_{y}$

3. $u_{L}>u_{y}>u_{1}$

$u_{L, y}=u_{y}$ being the axial slip in correspondence of the free end when yielding occurs and $u_{1}$ the value of slip corresponding to the residual value of the bond stress $\tau_{d}$.

In this way, different conditions can be determined for the definition of the axial stress - axial slip law, summarized in Figs. 7 and 8, related respectively to the Cases A and B. For what concerns

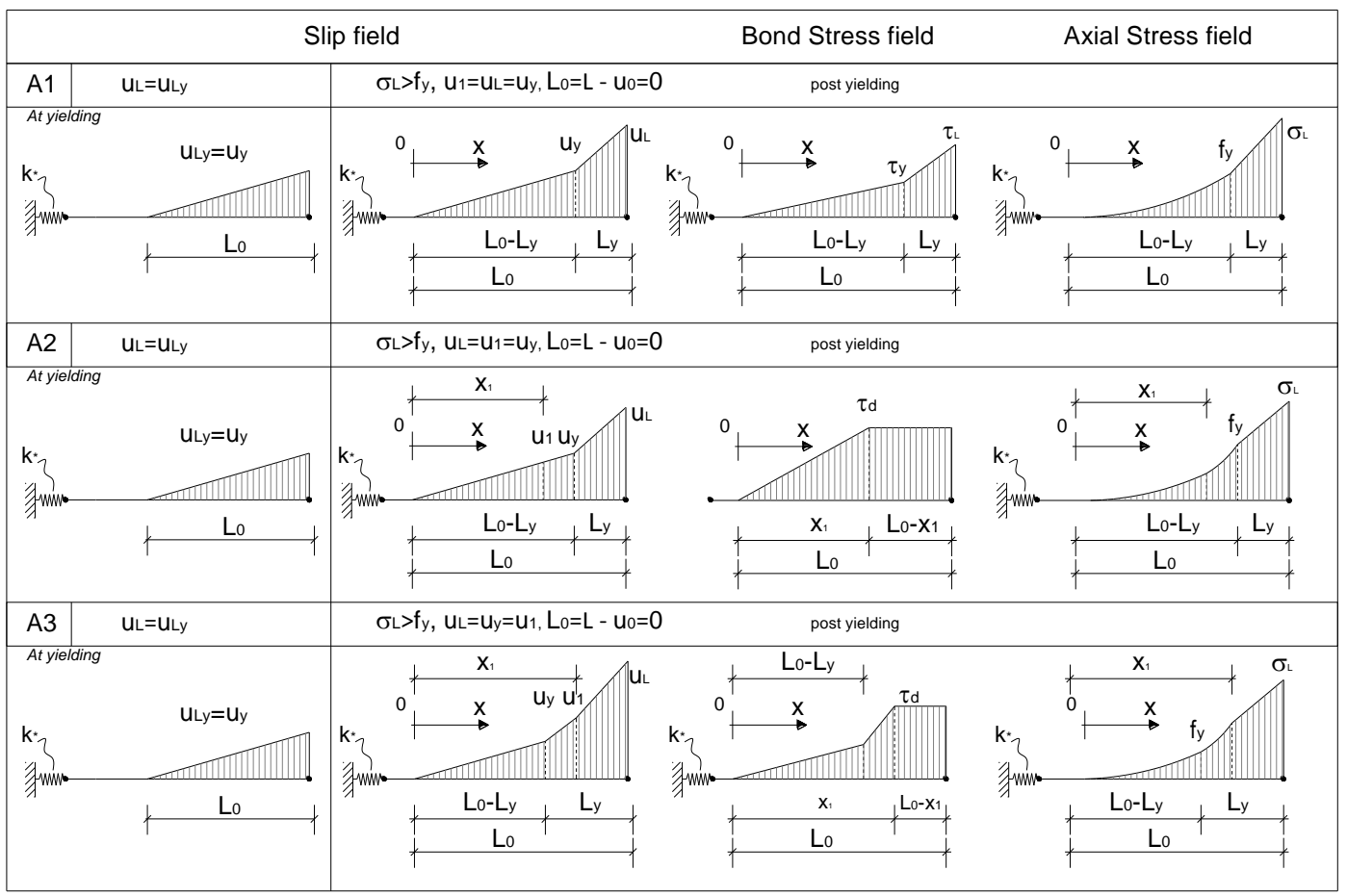

Fig. 7 Different cases considered for the analytical formulation for $L_{0}<L$ before and after yielding 


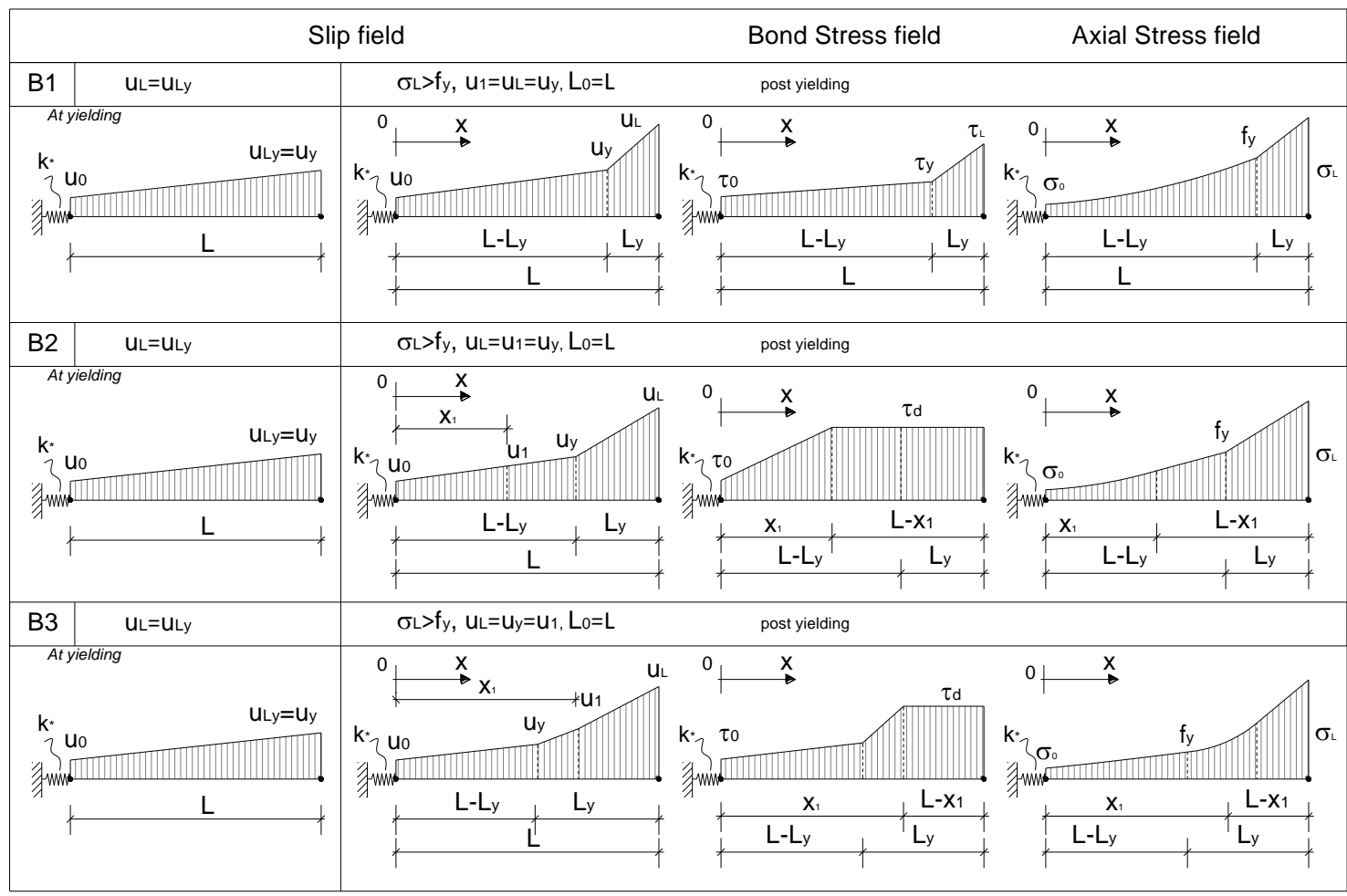

Fig. 8 Different cases considered for the analytical formulation for $L_{0}=L$ before and after yielding

cases $\mathrm{C}$ and $\mathrm{D}$, they coincide with the cases A until $L_{0}$ reaches $L$ (i.e., if the length of the bar involved in relative slip is lower than the total length of the bar), afterwards they can be reduced to the relevant cases B in relation to the values of the length involved in relative slip when yielding occurs. In the following pages, cases will be indicated with a tag containing the corresponding letter and number. As a consequence, the elaboration of the continuous axial stress-slip relationship for a steel reinforcement in a concrete block requires the strict control of the parameter $L_{0}$ (i.e., initial length involved in relative slip) and of the corresponding values of stress and slip when the yielding occurs. In the appendix to the present paper the elaboration of the slip model after yielding (i.e., for $\sigma_{L}>f_{y}$ ) is presented for general cases $\mathrm{A} 1, \mathrm{~A} 2, \mathrm{~A} 3$ and $\mathrm{B} 1, \mathrm{~B} 2, \mathrm{~B} 3$. A short formulation of the slip model until yielding is provided, suggesting to refer to the elaborations included in (Gigliotti 2002, Braga et al. 2012) for further details. In the equations and figures presented in the Appendix to the present work $L_{0}\left(\right.$ or $L_{1}$ or $L_{2}$ ) and $L_{y}$ are respectively the part of the bar involved in relative slip and that with stress higher than yielding strength.

\subsection{Numerical implementation in engineering software}

According to what presented and more extensively explained in the Appendix to the present work, a continuous axial stress-axial slip law, taking into account hardening phenomena of steel, can be derived for reinforcements embedded in concrete. The introduction of relative slip is necessary for the understanding of the cyclic behaviour of r.c. elements and structures and, in 
particular, for the determination of the levels of deformation induced in steel reinforcing bars. The analytical formulation of the hardening slip model allows to determine a continuous axial stressslip relationship that, generally, cannot be directly used in common engineering software. The problem of the transformation from the uniaxial stress-slip law $(\sigma-u)$ to the uniaxial stress-strain one $(\sigma-\varepsilon)$, necessary for the implementation of the model in numerical software, can be solved in the case of lumped plastic hinge models with fibre sections according to the formulation proposed by D'Amato et al. (2012). The axial displacements $u_{L}$ can be considered as the integrated axial displacement of a longitudinal bar including both steel deformation and bond slip phenomena, developed along the plastic hinge length. Adopting this simplification, a "pseudo-strain" $\left(\varepsilon^{*}\right)$ can be evaluated according to the Eq. (13), in which $L_{p}$ represents the plastic hinge length and $u_{L, t o t}$ the total relative slip, including elongation and anchorage slip

$$
\varepsilon^{*}=\frac{u_{L, t o t}}{L_{P}}
$$

The term "pseudo", referred to strains, implies that the $\left(\sigma^{-} \varepsilon^{*}\right)$ relationship is an abstraction of the $\left(\sigma-u_{L}\right)$ law necessary to implement the model in a fibre section model (D'Amato et al. 2012). For what concerns the definition of the plastic hinge length the expression proposed by Panagiotakos and Fardis (2001) is usually adopted in the present work

$$
L_{p}=L_{p l, c y}=0.12 \cdot L_{s}+0.014 a_{s l} d_{b} f_{y}
$$

$L_{s}$ being the shear span length, $a_{s l}$ a coefficient for slip equal to 1 if there is slippage of the longitudinal bars from their anchorage beyond the section of maximum moment, or to 0 if there is not slip, $d_{b}$ is the bar diameter and $f_{y}$ the yielding strength. In the present work, the value of $a_{s l}$ is assumed equal to zero, since the relative slip between bars and concrete are directly taken into consideration through the modified slip model. According to D'Amato (2009), $L_{s}$ can be assumed equal to half of the element's length, in good agreement with various formulations presented in the scientific literature (Paulay and Priestley 1992). The so evaluated $\left(\sigma-\varepsilon^{*}\right)$ relationship directly incorporates the bond-slip. According to D'Amato et al. (2012) the total relative slip $u_{L, T o t}$ occurring at the concrete crack is defined as presented by Eq. (12), $u_{L, A}$ and $u_{L, B}$ being the relative axial displacements including the bond slip related to blocks A and B respectively (Fig. 9)

$$
u_{L, t o t}=u_{L, A}+u_{L, B}
$$

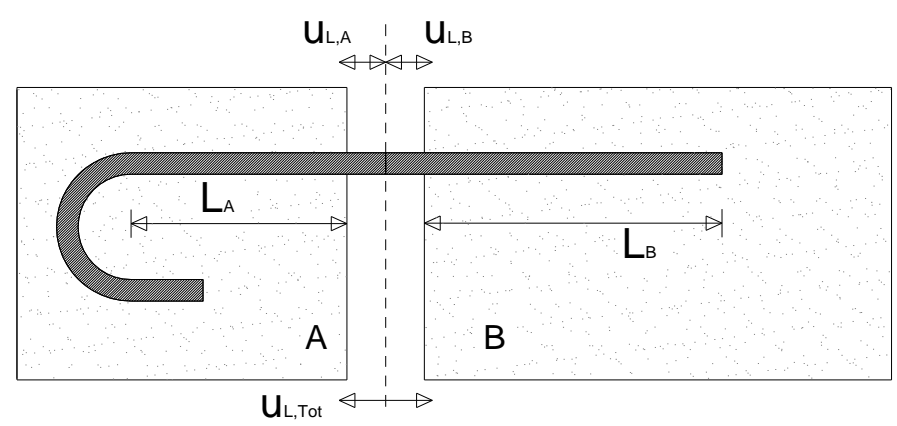

Fig. 9 Total relative slip in the concrete crack (D'Amato et al. 2012) 


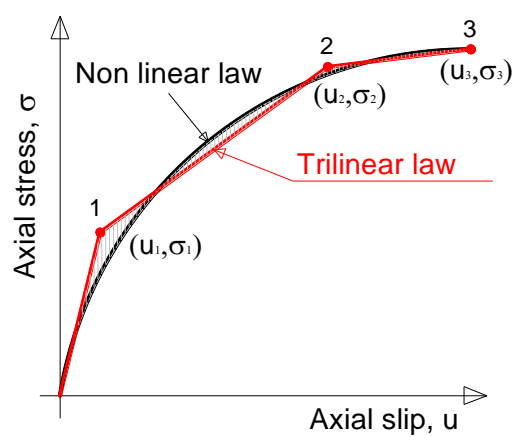

Fig. 10 Scheme of the trilinear law adopted on the basis of energy equivalence principle

The continuous $\left(\sigma-\varepsilon^{*}\right)$ law can be simplified into a trilinear relationship based on the energy equivalence principle, according to what presented by Braga et al. (2012) and simply schematized in Fig. 10. As a consequence, the two coordinates (i.e., slip and axial stress) of the three significant points shall be determined in the $(\sigma-u)$ relationship and then transformed into three $\left(\sigma^{-} \varepsilon^{*}\right)$ points adopting Eq. (13).

\section{Numerical application}

The comparison between experimental tests and numerical analyses on simple r.c. elements using the hardening slip model is provided; the present paper can be considered as an extension of the works by D'Amato et al. (2012), Gigliotti (2002) about the validation of the slip model. In particular, the cantilever columns analyzed by Saatcioglu and Ozcebe (1989) and by Tanaka and Park (1990), subjected to bidirectional loading histories, were used as case studies.

Simple cantilever elements were modelled with OpenSees software (Mazzoni et al. 2007) using a "Beam With Hinge (BWH)" element characterized by one plastic hinge at the base, where plastic deformations are expected, and an elastic central part. The base section was modelled as a fibre section for a plastic hinge length equal to the one defined by Eq. (14), adopting the BGL model (Braga et al. 2006, D'Amato 2009) for concrete, since able to represent the confinement contributions due to both longitudinal and transversal reinforcements, and the hardening slip model for reinforcements. The flexural behaviour of the section so obtained was coupled with the elastic modelling of the shear behaviour.

Since the hardening slip model provides an axial stress-slip law, the transformation from the derived $(\sigma-u)$ relationship to the axial stress-strain $(\sigma-\varepsilon)$ law, necessary for the implementation in the numerical software, was executed following the approach presented by Eq. (13).

In order to fully represent the process adopted for the determination of the axial stress-slip law for reinforcements, the numerical example of a single steel bar is developed and herein presented for each one of the two considered benchmarks. The procedure followed in the present work for the determination of the stress-strain relationship of steel bars in r.c. structural members under cyclic action can be summarized in the following steps:

Step 1. Determination of the stress-slip $(\sigma-u)$ law for the bars of the considered element's section, in relation to the length, the typology and the mechanical properties of the bar . 

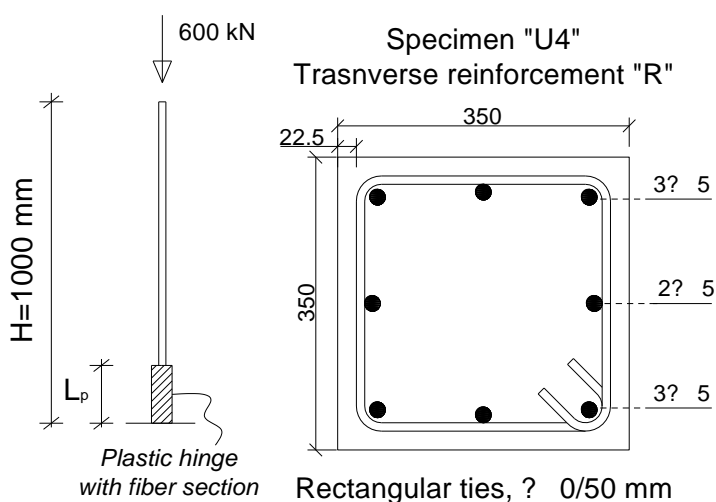

(a)

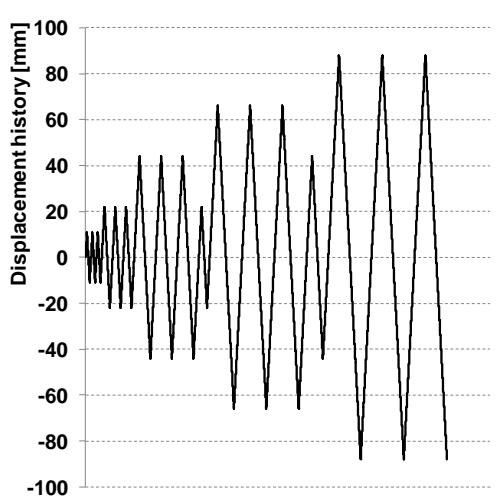

(b)

Fig. 11 Saatcioglu and Ozcebe (1989): (a) scheme of the section, (b) displacement history

Step 2. Determination of the stress-fictitious strain $\left(\sigma^{-} \varepsilon^{*}\right)$ and, if necessary, tri-linearization of the law with the energy equivalence principle.

Step 3. Non linear modelling of the r.c. element (or whole structure) adopting fibre section elements with combined flexural and shear behaviour: application of the $\sigma^{-\varepsilon^{*}}$ law to the steel fibres.

Step 4. Execution of non linear analysis on r.c. elements (or structures) and determination of axial stress histories on bars.

Step 5. Elaboration of a bare bar model (e.g., non linear spring element) calibrated on the base of experimental tests' results.

Step 6. Execution of non linear analysis on the bar model subjected to the axial stress histories and determination of the real strain values.

In the following paragraphs the procedure is directly applied to the two selected case studies.

\subsection{Saatcioglu and Ozcebe - specimen U4}

The benchmark, according to what presented in Fig. 11(a), consists of a cantilever column with height equal to $1000 \mathrm{~mm}$ (Berry and Parrish 2004) characterized by a square $350 \times 350 \mathrm{~mm}$ section, provided by 8 longitudinal reinforcements of diameter $25 \mathrm{~mm}$ and transversal stirrups of diameter $10 \mathrm{~mm}$ and spacing $100 \mathrm{~mm}$. The axial load applied at the top of the column is equal to $600 \mathrm{kN}$ while the displacement history is presented in the Fig. 11(b).

\subsubsection{Axial stress-slip relationship for steel bar}

The considered bar is characterized by a total length $L$ equal $1000 \mathrm{~mm}$, diameter $D$ equal to 25 $\mathrm{mm}$, mean yielding and tensile strength respectively equal to 438 and $540 \mathrm{MPa}$, according to what specified in PEER structural database (Berry et al. 2004). The bond-stress slip law is defined according to Model Code 1990, considering a residual bond stress $\tau_{d}$ equal to $1.70 \mathrm{MPa}$ and a corresponding slip $u_{1}$ equal to $0.1 \mathrm{~mm}$, as well as already presented by Braga et al. (2009).

The formulation of the anchorage length $L_{0}$ was derived by Braga et al. (2012) starting from equilibrium, compatibility and constitutive equations applied to the considered specimen. Before the achievement of yielding strength, the slip and the bond stress fields are expressed respectively 
by Eqs. (1) and (4); the equilibrium and compatibility Eqs. (7) and (8) turn into

$$
\begin{gathered}
\sigma(x)=\frac{4}{D} \int_{0}^{x} \tau(x) d x+\frac{F_{h}}{A_{b}}=\frac{4 \tau_{d}}{D u_{1}} \cdot\left[u_{0} x+\frac{x^{2}}{2 L}\left(u_{L}-u_{0}\right)\right]+k_{h}^{*} u_{0} \\
u_{E}(x)=\int_{0}^{L} \varepsilon_{E}(x) d x=\frac{1}{E_{s}} \int_{0}^{L} \sigma(x) d x
\end{gathered}
$$

$u_{E}$ being the elastic displacement, $E_{s}$ the elastic modulus of steel and $L$ the length of the bar (in the hypothesis of full bar length involved in relative slip). Stress and elastic displacement at the free end are consequently provided by

$$
\begin{gathered}
\sigma_{L}=\frac{2 \tau_{d} L}{D u_{1}}\left(u_{0}+u_{L}\right)+k_{h}^{*} u_{0} \\
u_{E}(L)=u_{L}-u_{0}=\frac{1}{E_{s}}\left[\frac{2 \tau_{d} L^{2}}{3 D u_{1}} \cdot\left(2 u_{0}+u_{L}\right)+k_{h}^{*} u_{0} L\right]
\end{gathered}
$$

If the displacement at the hooked end $\left(u_{0}\right)$ is null, the anchorage length $L_{0}$ can be expressed by $L_{0}=\sqrt{\frac{3}{2} \frac{E_{s} u_{1}}{\tau_{d}} D}$, simply turning into Eq. (20)

$$
L_{0}=D \sqrt{\frac{3 \pi}{2} \frac{E_{s}}{E_{d}}}
$$

in which $E_{d}=\frac{\tau_{d}}{u_{1}} \cdot \pi D . L_{0}$ can be considered constant until $u_{L} \leq u_{1}$ and afterwards it increases with the increase of $u_{L}$ (i.e., the external load applied on the bar). In the present case, the anchorage length before yielding and for $u_{L} \leq u_{1}$ is then equal to: $L_{0}=D \sqrt{\frac{3 \pi}{2} \frac{E_{s}}{E_{d}}}=680.7 \mathrm{~mm}$. The value of the initial anchorage length $L_{0}$ is then lower than $L$; this means that the simplification of assuming the slip at the anchored end equal to zero $\left(u_{0}=0\right)$ can be executed, even if the exact analytical solution of the problem will provide slip values very small but not properly null. Five significant points can be then determined for the constitutive law of steel bars:

- Point A corresponds to the condition in which the limit bond stress $\tau_{d}$ is reached at the free end: $u_{L, A}=u_{1}$.

- Point B corresponds to the distribution of bond strength along all the length of the rebar (L), with consequently $u_{0, B}=0$ and $L_{0}=L$.

- Point $C$ corresponds to the condition in which all the length of the bar is characterized by a bond stress equal to $\tau_{d}$ : as a consequence, the limit condition is defined by $u_{0, C}=u_{1}$.

- Point Y corresponds to the condition in which the axial stress in correspondence of the free end is equal to the yielding strength $\left(\sigma_{L, Y}=f_{y}\right)$, with relative slip $u_{L, y}$.

- Point $U$ corresponds to the to the condition in which the axial stress at the free end is equal to the ultimate strength $\left(\sigma_{L, U}=f_{u}\right)$, with relative slip $u_{L, u}$.

Fig. 12 shows the elaboration of the hardening slip model considering the progressive increase of relative slip and axial stress in the case $u_{1}<u_{y}$. The expressions for axial stress and relative slip 

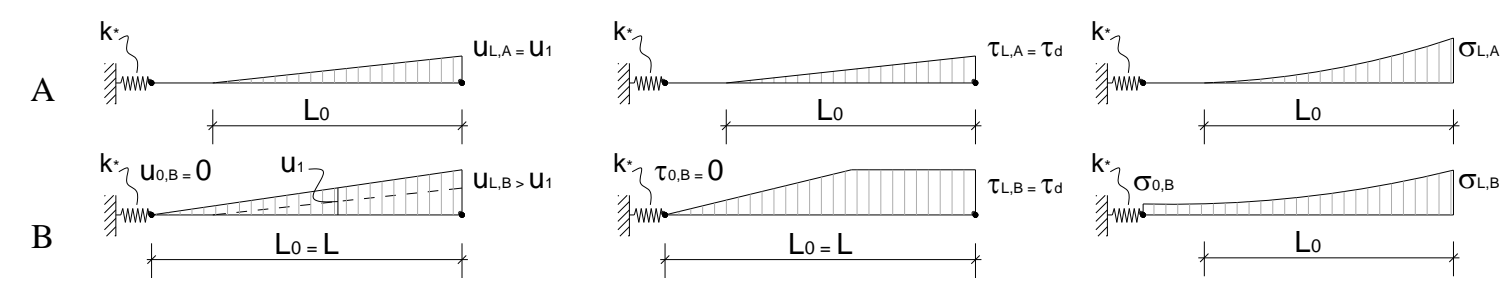

C
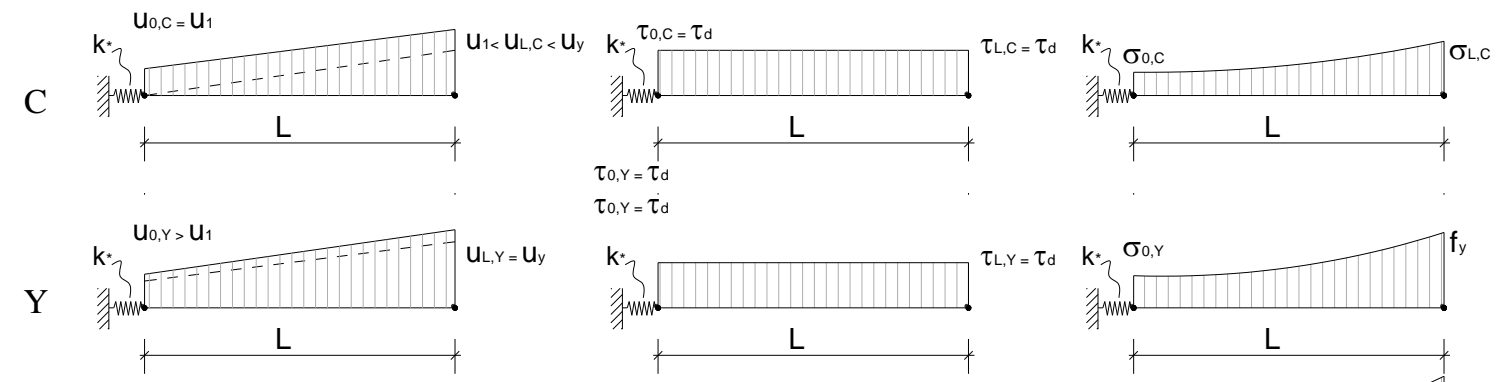

$\tau_{0, Y}=\tau_{d}$
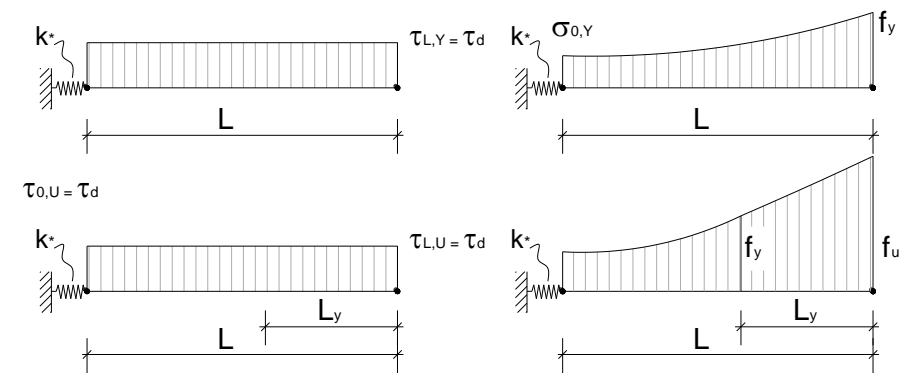

$\mathrm{U}$
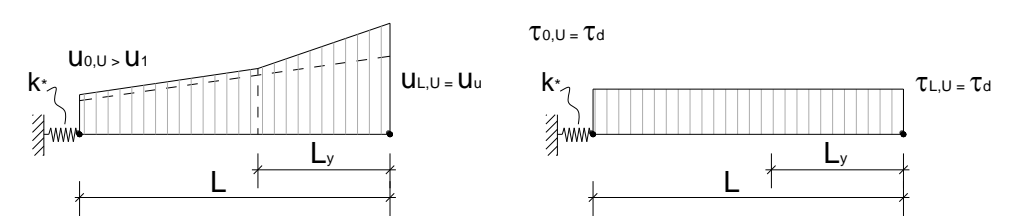

Fig. 12 Axial slip, bond stress and axial stress along the bar for initial condition $L_{0}<L$

are defined according to the equations presented in the previous paragraphs.

The axial stress in correspondence of the free length of the bar for point $\mathrm{A}$ can be evaluated through Eq. (21); in a similar way, Eq. (22) is able to describe the behaviour of the axial stress field till the limit slip $u_{L A}=u_{1}$ is reached

$$
\begin{gathered}
\sigma_{L 0}=\sigma_{A}=\frac{2 \tau_{d} L_{0} u_{L}}{D u_{1}}=92.6 \mathrm{MPa} \\
\sigma_{L}\left(u_{L}\right)=\frac{2 \tau_{d} L_{0} u_{L}}{D u_{1}}
\end{gathered}
$$

The second branch of the stress-slip relationship $(\mathrm{AB})$ is determined between the already defined point $\mathrm{A}$ and the one corresponding to the condition $L_{0}=L$ (point $\mathrm{B}$ ). In this case, the axial stress $\sigma_{B}$ is defined by Eq. (23) while the generic axial stress is defined according to Eq. (24)

$$
\begin{gathered}
\sigma(L)=\sigma_{B}=\frac{2 \tau_{d} L\left(2 u_{L}-u_{1}\right)}{D u_{L B}}=246.6 \mathrm{MPa} \\
\sigma_{L}\left(u_{L}\right)=\frac{2 \tau_{d} L_{0}\left(2 u_{L}-u_{1}\right)}{D u_{L}}
\end{gathered}
$$

In the considered case, the stress in correspondence of point B is still lower than the yielding strength: as a consequence, the third branch (BC) of the stress-slip law is defined considering as limit condition $u_{O C}=u_{1}$ and Eqs. (25) and (26) provide the following values for the axial stress 
and slip. The trend of axial stresses in BC branch is defined according to Eq. (27)

$$
\begin{gathered}
\sigma_{C}=\frac{4 \tau_{d}}{D} L+k_{h}^{*} u_{1}=355.2 \mathrm{MPa} \\
u_{L C}=\frac{2 \tau_{d} L^{2}}{E_{s} D}+\left(\frac{L}{E_{s}} k_{h}^{*}+1\right) u_{0}=1.144 \mathrm{~mm} \\
\sigma_{L}\left(u_{L}\right)=\frac{2 \tau_{d} L \cdot\left(2 u_{1} u_{L}-u_{0}^{2}-u_{1}^{2}\right)}{D u_{1}\left(u_{L}-u_{0}\right)}+k_{h}^{*} u_{0}
\end{gathered}
$$

Since yielding strength is not yet reached in correspondence of point $\mathrm{C}$, a fourth branch $(\mathrm{CY})$ can be determined, considering the Eqs. (28)-(29) for the evaluation of $u_{0 Y}$ and $u_{L Y}$, moreover, Eq. (30) can be adopted for the description of the axial stress slip

$$
\begin{gathered}
u_{0 Y}=\frac{\left(f_{y}-4 \tau_{d} L / d\right)}{k^{*}{ }_{h}}=0.199 \mathrm{~mm} \\
u_{L Y}=\frac{2 \tau_{d} L^{2}}{E_{s} D}+u_{O Y}\left(\frac{L}{E_{s}} k_{h}^{*}+1\right)=1.637 \mathrm{~mm} \\
\sigma_{L}\left(u_{L}\right)=\frac{4 \tau_{d}}{D} L+k_{h}^{*} u_{0}
\end{gathered}
$$

The final branch of the axial stress-slip law, once that yielding is reached, is described by the equations provided for case $\mathrm{B} 3$, since $\sigma_{L}>f_{y}, u_{1}<u_{\mathrm{y}} \leq u_{L}, u_{0}>0$. The limit condition for this branch is the achievement of the ultimate tensile strength $f_{u}$, with the following values of slip in correspondence of the two ends defined by Eqs. (31)-(32)

$$
\begin{gathered}
u_{0 u}=\frac{\left(f_{u}-4 \tau_{d} L / d\right)}{k^{*}{ }_{h}}=0.322 \mathrm{~mm} \\
u_{L u}=\frac{2 \tau_{d} L^{2}}{E_{s} D}+u_{0 u}\left(\frac{L}{E_{s}} k_{h}^{*}+1\right)=33.25 \mathrm{~mm}
\end{gathered}
$$

The constitutive axial stress-slip relationship obtained is presented in Fig. 11(a); an idealized trilinear law shall be then determined using the equivalence energy principle, allowing the determination of the three significant points defining the trilinear law presented in Fig. 11(b).

\subsubsection{Axial stress- pseudo strain $\left(\sigma-\varepsilon^{*}\right)$ relationship for steel bar and global results}

The shift from the so defined axial stress-slip law to the axial stress - pseudo strain law is necessary to introduce the hardening slip relationship in the non linear fibre model in OpenSees (Mazzoni et al. 2007). The $\left(\sigma^{-} \varepsilon^{*}\right)$ law can be evaluated through Eq. (10), in which $L_{p}$ represents the plastic hinge length; the obtained relationship represents a "pseudo steel stress-strain relationship", in which $\varepsilon^{*}$ is affected by the plastic hinge's length. The equivalent trilinear $(\sigma-u)$ relationship (Fig. 13(b)) can be used for the determination of a corresponding trilinear $\left(\sigma^{-} \varepsilon^{*}\right)$ one. 


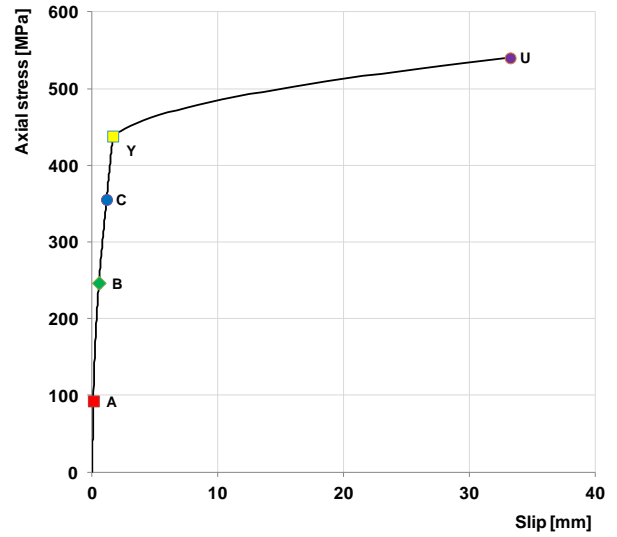

(a)

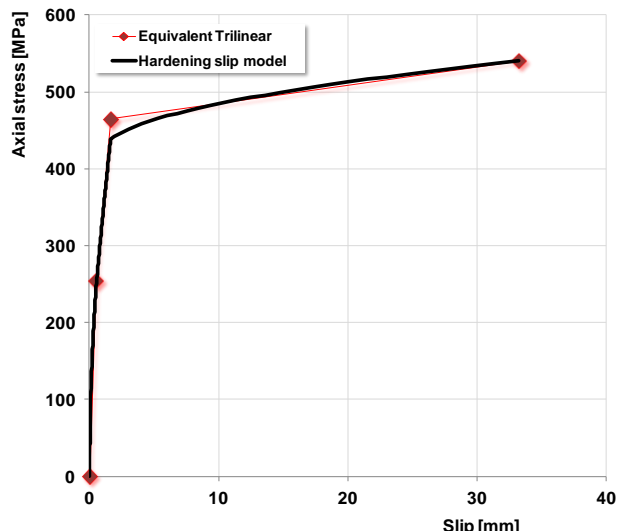

(b)

Fig. 13 Saatcioglu and Ozcebe (1989): (a) axial stress-slip law, (b) trilinear equivalent law

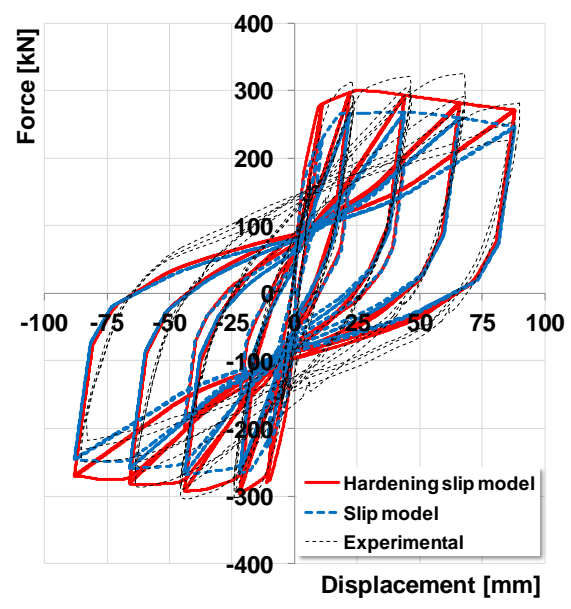

(a)

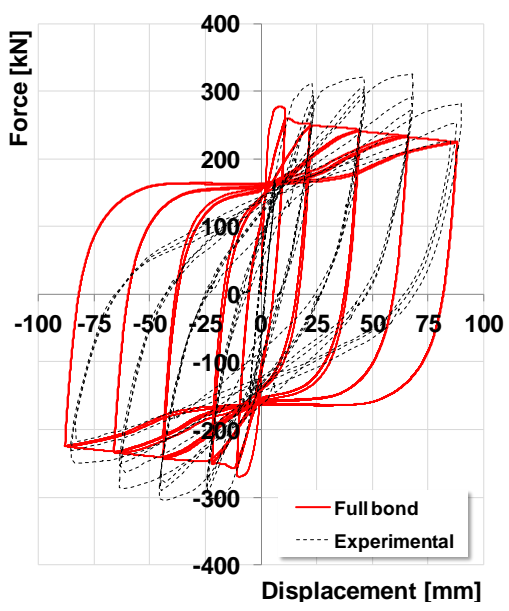

(b)

Fig. 14 Saatcioglu and Ozcebe specimen comparison between numerical/experimental results: (a) slip and the hardening slip models, (b) hardening slip and full bond models

The pseudo stress-strain law is implemented in OpenSees using a trilinear hysteretic material.

Table 1 summarizes the values of slip and axial stresses obtained for the 5 points characterizing the constitutive $(\sigma-u)$ relationship, while in Table 2 the equivalent points adopted for the trilinear law are provided. Fig. 14(a) presents the comparison between the experimental tests' results obtained by Saatcioglu and Ozcebe (1989) and the numerical predictions using the slip and the hardening slip models previously illustrated; Fig. 14(b) shows the comparison between experimental and numerical results obtained using a full bond model including hardening effects.

As visible from Fig. 14, the results of numerical analyses including relative slip for steel bars are in better agreement with the experimental ones respect to the adoption of perfect bond models: looking at the dissipative behaviour of the element (in terms of energy density), the use of the slip model leads to an underestimation of the dissipated energy, while in the case of full bond constitutive law the obtained dissipated energy is strongly higher than the one coming from 


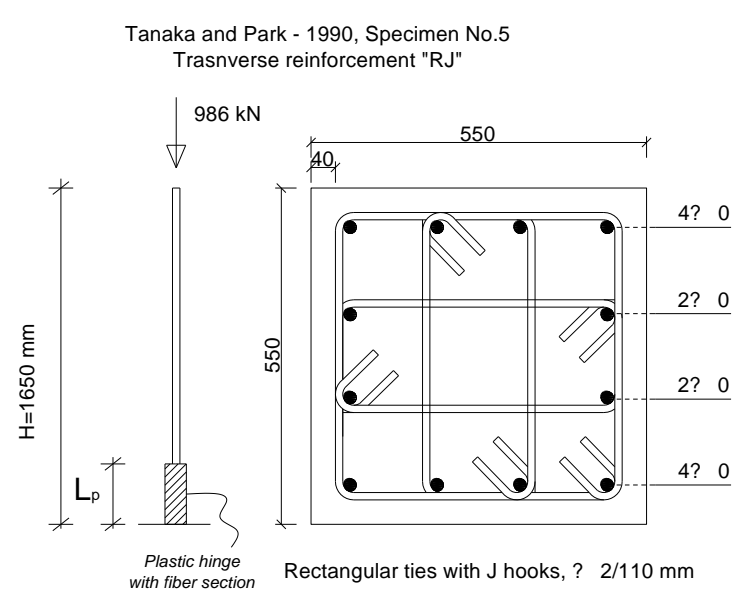

(a)

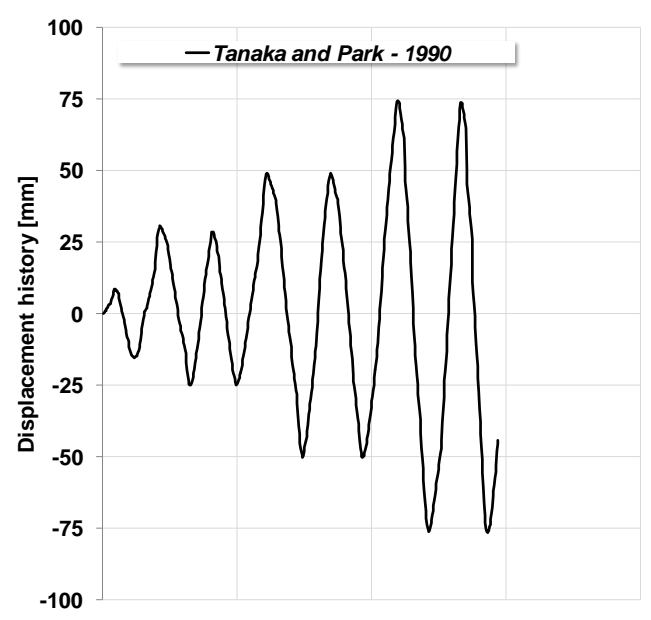

(b)

Fig. 15 Tanaka and Park, No. 5 (1990): (a) scheme of the section, (b) displacement history

experimental test. At a global level, the adoption of the hardening slip model instead of the slip model proposed by Braga et al. (2006) does not provide a significant improvement in the results: as shown by the Fig. 14, the difference in terms of dissipated energy in the adoption of the slip or of the hardening slip model is equal to about the $6.0 \%$.

\subsection{Tanaka and Park - specimen n`5}

The benchmark consists of a cantilever column with height equal to $1650 \mathrm{~mm}$ (Berry et al. 2004) characterized by a square $550 \times 550 \mathrm{~mm}$ section, provided by 12 longitudinal bars of diameter $20 \mathrm{~mm}$ and transversal stirrups of diameter $10 \mathrm{~mm}$ and spacing $110 \mathrm{~mm}$ (Fig. 15(a)). The axial load applied at the top of the column is equal to $986 \mathrm{kN}$ while the displacement history is presented in the Fig. 15(b).

\subsubsection{Axial stress-slip relationship for steel bar and results}

The bar considered has a total length $L$ of $1650 \mathrm{~mm}$, in relation to the size of the tested column and to the specifications presented in PEER structural database, diameter $D$ equal to $20 \mathrm{~mm}$, mean yielding and tensile strength respectively equal to 511 and $675 \mathrm{MPa}$ The bond-stress slip law is assumed on the base of the considerations provided by Model Code 1990, considering a residual bond stress $\tau_{d}$ equal to $2.87 \mathrm{MPa}$ and a corresponding slip $u_{l}$ equal to $0.40 \mathrm{~mm}$ for ribbed bars. The anchorage length before yielding and for $u_{L} \leq u_{1}$ is defined according to the Eq. (20). In the present case the anchorage length expressed by Eq. (20) can be so evaluated as:

$$
L_{0}=D \sqrt{\frac{3 \pi}{2} \frac{E_{s}}{E_{d}}}=928.1 \mathrm{~mm}
$$

The value of the initial anchorage length $L_{0}$ is then lower than $L$; this means that the simplification of assuming the slip at the anchored end equal to zero $\left(u_{0}=0\right)$ can be executed, even if the exact analytical solution of the problem will provide slip values very small but not 
properly null. In the present case, the analysis of the bar evidenced three significant points necessary for the representation of the constitutive law:

- Point A: condition in which the limit bond stress $\tau_{d}$ is reached at the free end $\left(u_{L, A}=u_{1}\right)$.

- Point Y: condition in which the axial stress in correspondence of the free end is equal to the yielding strength $\left(\sigma_{L, Y}=f_{y}\right)$, with relative slip $u_{L, y}$.

- Point U: condition in which the axial stress at the free end is equal to the ultimate strength ( $\sigma_{L, U}=f_{u}$ ), with relative slip $u_{L, u}$;

The expressions defining the axial stress and the relative slip along the bar are defined according to the equations of equilibrium and compatibility of displacements presented in the previous paragraphs. The axial stress in correspondence of the free length of the bar for point A can be evaluated through

$$
\sigma_{L 0}=\sigma_{A}=\frac{2 \tau_{d} L_{0} u_{L A}}{D u_{1}}=266.36 \mathrm{MPa}
$$

Moreover, Eq. (35) is able to describe the behaviour of the axial stress field till the limit slip $u_{L A}=u_{1}$ is reached

$$
\sigma_{L}\left(u_{L}\right)=\frac{2 \tau_{d} L_{0} u_{L}}{D u_{1}}
$$

Differently for what was found for the smooth bar of the specimen U4 by Saatcioglu and Ozcebe (1989), in the present case, the increase of the axial slip leads to the attainment of the yielding point before the involvement of the whole length of the bar in relative slip. As a consequence, the second branch of the stress-slip relationship (AY) is determined between the already defined point $\mathrm{A}$ and the one corresponding to yielding (Y). In the branch AY the length directly involved in relative slip is defined by

$$
L_{1}\left(u_{L}\right)=L_{0} \cdot\left(\frac{u_{L}^{3}}{u_{1} \cdot\left(u_{1}^{2}-3 \cdot u_{1} u_{L}+3 u_{L}^{2}\right)}\right)^{\frac{1}{2}}
$$

in which $u_{L}$ is the slip at the end of the bar that increases from $u_{L A}=u_{1}$ to $u_{L Y}$.

The trend of axial stresses in the branch AY is defined according to the Eq. (37)

$$
\sigma_{L}\left(u_{L}\right)=\frac{2 \tau_{d}\left(2 u_{L}-u_{1}\right) L_{1}}{D u_{L}} \text {, being } L_{1}=L_{1}\left(u_{L}\right)
$$

The axial slip corresponding to yielding $\left(u_{L Y}\right)$ can be evaluated through Eq. (37) in which the value of $L_{1}$ when yielding occurs is defined as a function of $u_{L Y}$ according to Eq. (36). The value of axial slip when yielding occurs is consequently equal to $u_{L Y}=1.122 \mathrm{~mm}$; moreover, the corresponding length involved in relative slip is equal to $L_{1}\left(u_{L Y}\right)=L_{1}=1084 \mathrm{~mm}$. In the considered case, once that yielding is reached, the length of the bar involved in relative slip is still lower than the total length of the bar itself (i.e., $L_{1}<L$ ), being, moreover, $u_{L Y}>u_{1}$ and $u_{0}=0$. As a consequence, the equations provided for case A3 can be adopted to describe the axial stress-slip law once that yielding is overpassed. The third significant point describing the axial stress-slip relationship is the one corresponding to the reaching of the ultimate condition (U). The trend of axial stress on the rebar with the increase of axial slip can be expressed by Eq. (38) 


$$
\sigma_{L 2}\left(u_{L}\right)=\frac{2 \tau_{d}\left(2 L_{2} u_{L Y}-L_{1} u_{1}\right)}{D u_{L Y}}, \text { being } L_{2}=L_{2}\left(u_{L}\right)
$$

When the ultimate value of stress $f_{u}$ is reached, the maximum length of the bar involved in relative slip is obtained from Eq. (31) in which $\sigma_{L 2}=f_{u}$. As a consequence, $L_{2}=L\left(f_{u}\right)=1369 \mathrm{~mm}$. Axial slip in the branch YU can be then derived from Eq. (39), in which $L_{2}=L_{2}\left(u_{L}\right)$.

$$
\begin{aligned}
& u_{L}=\frac{-3 D E_{s} \cdot\left(L_{2}-L_{1}\right) u_{L y}^{2} \cdot\left(f_{y}-E_{h} \varepsilon_{p}\right)}{3 D E_{h} E_{s} u_{L y}^{2}}+ \\
& +\frac{2\left(E_{h} L_{1}{ }^{2}\left(u^{2}{ }_{1}-3 u_{1} u_{L y}+3 u_{L y}{ }^{2}\right)+3 E_{s} \tau_{d} u_{L y}\left(L_{2}-L_{1}\right)\left(-L_{1} u_{1}+L_{2} u_{L y}+L_{1} u_{L y}\right)\right)}{3 D E_{h} E_{s} u_{L y}^{2}}
\end{aligned}
$$

The ultimate slip $u_{L u}$ can be determined from Eq. (39) in which $L_{2}=L\left(f_{u}\right)$ and consequently $u_{L u}=23.8 \mathrm{~mm}$. The constitutive axial stress-slip relationship obtained is presented in Fig. 14; an idealized trilinear law shall be then determined using the equivalence energy principle. The shift from the trilinear axial stress-slip law to the axial stress-pseudo strain one is necessary to implement the constitutive relationship into OpenSees software. Table 1 summarizes the values of slip and axial stresses obtained for the 3 points characterizing the constitutive $(\sigma-u)$ relationship, while in Table 2 the equivalent points adopted for the trilinear law are provided. As visible from Fig. 17 the results of numerical analyses including relative slip for steel bars, at a global level, are in better agreement with the experimental ones with respect to the adoption of perfect bond models: looking at the dissipative behaviour of the element (in terms of energy density), as well as already evidenced for the other considered specimen.

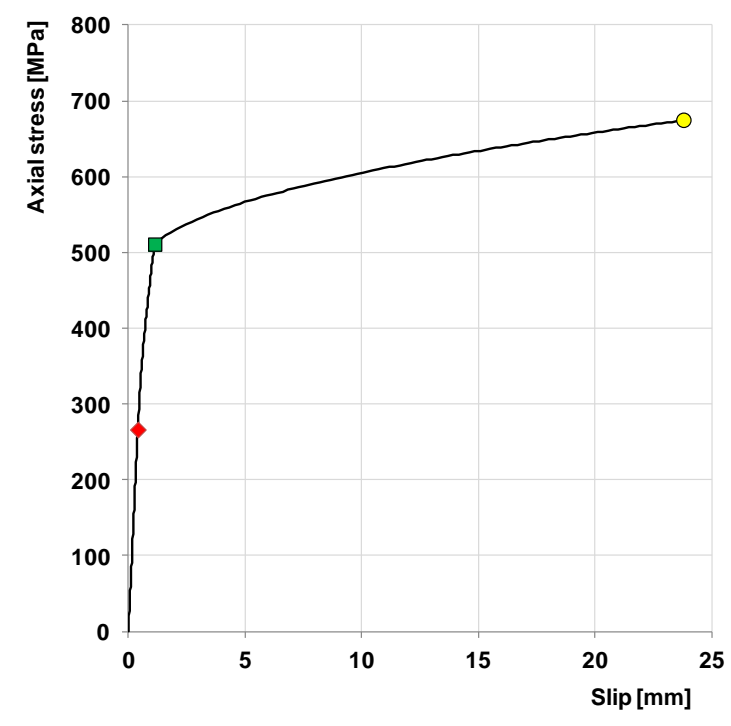

(a)

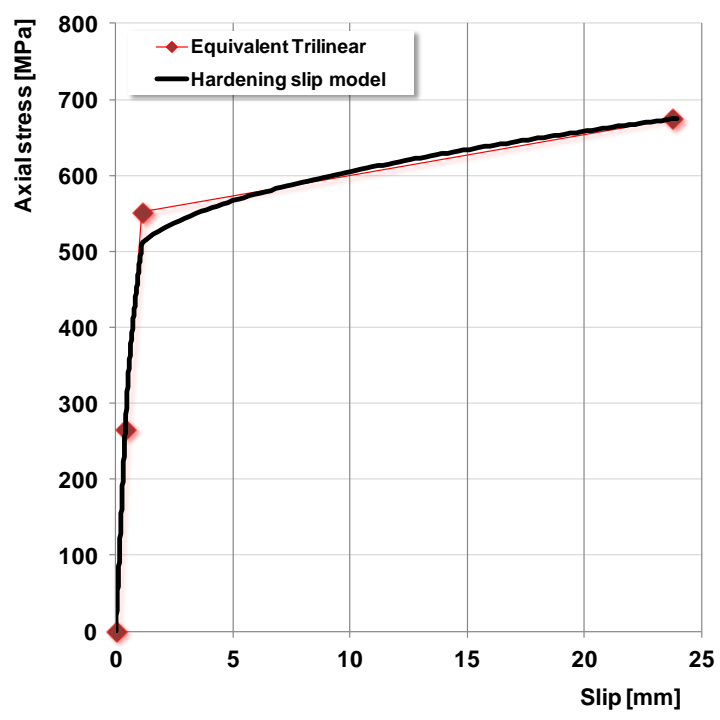

(b)

Fig. 16 Tanaka and Park (1990): (a) axial stress-slip law, (b) trilinear equivalent law 


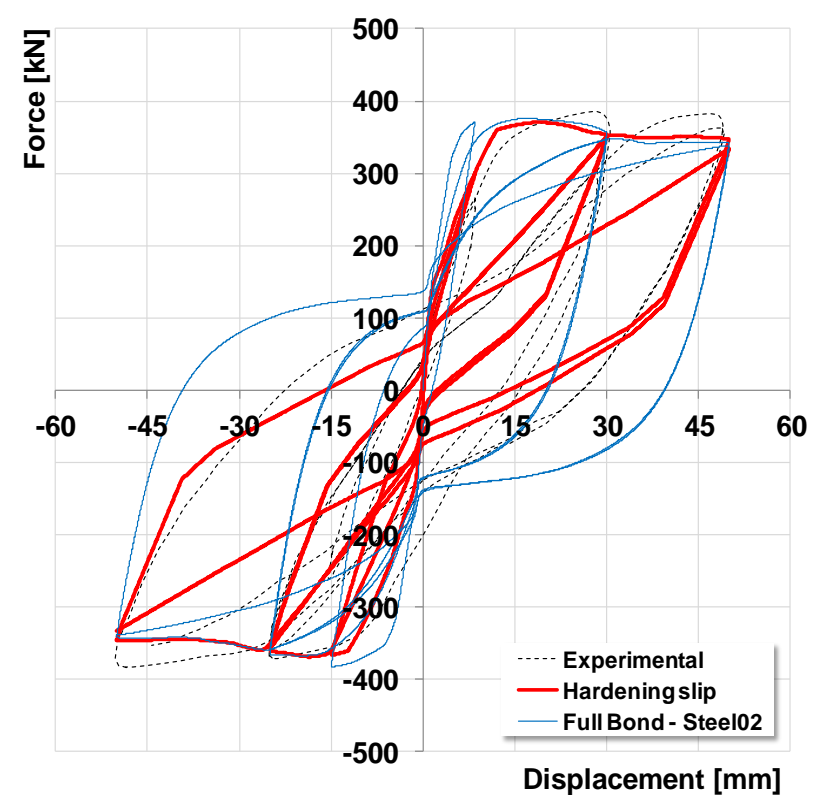

Fig. 17 Tanaka and Park (1990): numerical and experimental results (slip and full bond models)

Table 1 Significant points of the axial stress-slip relationship for the two considered benchmarks

\begin{tabular}{ccccc}
\hline \hline & \multicolumn{2}{c}{ Saatcioglu and Ozcebe (1989) } & \multicolumn{2}{c}{ Tanaka and Park (1990) } \\
\cline { 2 - 5 } & Slip [mm] & Axial stress [MPa] & Slip [mm] & Axial stress [MPa] \\
\hline A & 0.100 & 92.6 & 0.40 & 266.4 \\
B & 0.534 & 246.5 & - & - \\
C & 1.144 & 355.3 & - & - \\
Y & 1.637 & 438.0 & 1.12 & 511.0 \\
U & 33.25 & 540.0 & 23.78 & 675.0 \\
\hline
\end{tabular}

Table 2 Trilinear equivalent axial stress-slip relationship for the two considered benchmarks

\begin{tabular}{cccccc}
\hline \hline & \multicolumn{2}{c}{ Saatcioglu and Ozcebe (1989) } & \multicolumn{2}{c}{ Tanaka and Park (1990) } \\
\cline { 2 - 6 } & Slip [mm] & Axial stress [MPa] & Slip [mm] & Axial stress [MPa] \\
\hline Point & 1 & 0.534 & 254.6 & 0.40 & 266.4 \\
Point & 2 & 1.637 & 464.1 & 1.12 & 551.9 \\
Point & 3 & 33.247 & 540.0 & 23.8 & 675.0 \\
\hline
\end{tabular}

\subsection{Determination of the axial stress-strain histories on reinforcements}

The axial stress coming from numerical analyses can be considered correctly representative of the effective condition of bars embedded in concrete, while the values of pseudo-strain are affected by the plastic hinge length, as widely presented in the previous paragraphs. As a consequence, the real strain on bars, including the relative slip between steel and concrete, shall be evaluated separately on the base of the obtained axial stress histories. 

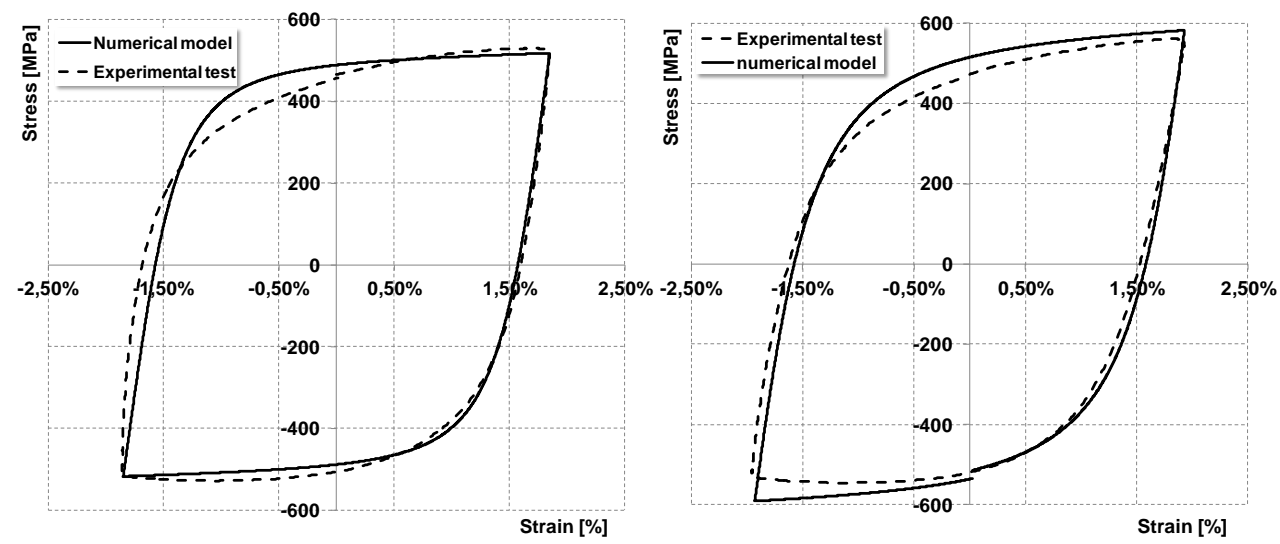

Fig. 18 Comparison of experimental/numerical results for bars under cyclic action $(\Delta \varepsilon) \pm 2.2 \%)$

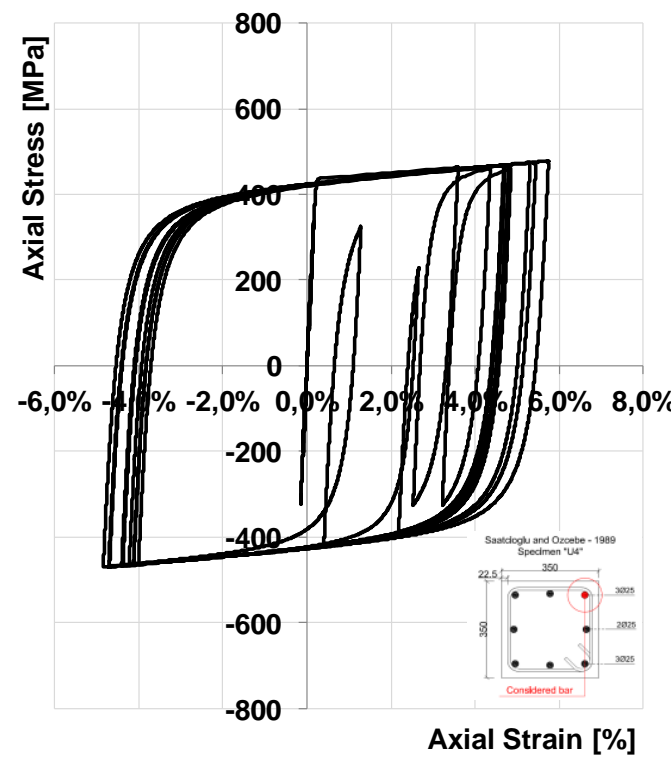

(a)

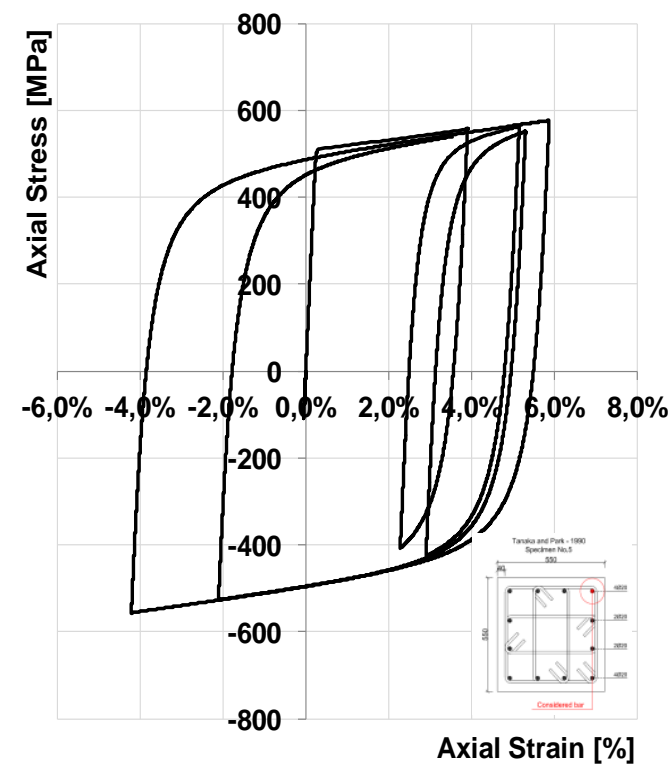

(b)

Fig. 19 Stress-strain history for external upper steel bar (a) Saatcioglu and Ozcebe (1989), (b) Tanaka and Park (1990)

The determination of the stress-strain relationship due to cyclic action of steel bars can be achieved, for example, elaborating a model of a bare bar and subjecting it to the axial stress histories derived from the numerical analysis on the structural element including relative slip.

In the present work, the bar model has been elaborated using a non linear spring element with a constitutive relationship calibrated on the base of the results of cyclic tests on reinforcements. The calibration procedure takes into account only the first tension-compression cycle, before buckling occurs (Braconi et al. 2013). The Menegotto-Pinto model (Menegotto and Pinto 1973), able to represent Baushinger effect and hardening phenomena has been adopted: relative slip can be neglected since directly considered in the global analyses for the determination of axial stress. The 
Menegotto-Pinto law was calibrated according to the results of experimental tests on a wide set of steel reinforcing bars under low-cycle fatigue (Braconi et al. 2014, Caprili and Salvatore 2015); a good estimation for the first tension-compression cycle was obtained (Fig. 18).

Fig. 18 shows the comparison between experimental and numerical results, while Figs. 19(a)(b) show the stress-strain histories obtained for one of the upper steel reinforcements of the base section of Saatcioglu and Ozcebe specimen U4 and Tanaka and Park's benchmark ${ }^{\circ} 5$. Steel bars are able to complete tension/compression cycles with maximum deformation in tension equal to about $6 \%$ and minimum deformation in compression up to $-4 \%$.

\section{Conclusions}

In the present work a simplified model for the representation of the behaviour of steel bars in r.c. structures under seismic action, including relative slip and hardening phenomena, is presented. The hardening slip model can be considered an improvement of the slip model proposed by Braga et al. (2012), in which the simplification of an elasto-plastic relationship for steel bars was assumed.

The necessity of a model taking into account relative slip between steel bars and surrounding concrete was able to represent the global behaviour of structures and the local cyclic/seismic behaviour of bars was widely evidenced in the past literature. The slip model proposed by Braga $e t$ al. (2012) reproduce the structural cyclic behaviour of elements and sub-assemblages (Gigliotti 2002, D'Amato et al. 2012) without being able, on the other hand, to determine the stress-strain histories on bars due to the simplification adopted for the constitutive law for steel, not including hardening phenomena. In this context, the improvement due to the hardening slip model is necessary to determine the cyclic behaviour of steel reinforcing bars under seismic actions. The relationship is based on the slip model proposed by (Braga et al. 2012) assuming an elastic-plastic with hardening simplification; a continuous axial stress-slip relationship is so derived and a further shift from axial slip to axial slip, necessary for the implementation in engineering software, can be executed according to what already presented by D'Amato et al. (2012).

In the present paper the complete analytical formulation of the post-yielding behaviour of steel reinforcing bars according to the hardening slip model is presented. The application to two simple benchmarks, i.e., the cantilever columns presented by Saatcioglu and Ozcebe (1989) and by Tanaka and Park (1990), highlights the ability of the hardening slip model to correctly represent both the global structural behaviour of the element and the local stress-strain histories on steel reinforcing bars, in terms of strain and dissipated energy, joined with the easiness in the application in engineering software according to what already presented in D'Amato et al. (2012).

\section{References}

Barry, M., Parrish, M. and Eberhard, M. (2004), PEER Structural Performance Database - User's manual Pacific Earthquake Engineering Research Center University of California, Berkeley.

Braconi, A., Braga, F., Caprili, S., Gigliotti, R. and Salvatore, W. (2012), "Ductility demand on steel reinforcing bars in concrete buildings", Proceedings of $11^{\text {th }}$ International Conference on Computational Structures Technology, Dubrovnik, Croatia.

Braconi, A., Braga, F., Caprili, S., Gigliotti, R. and Salvatore, W. (2013), "Influence of low-cycle fatigue and corrosion phenomena on the ductile behaviour of steel reinforcing bars", $4^{\text {th }}$ ECCOMAS Thematic 
Conference on Computational Methods in Structural Dynamics and Earthquake Engineering, Kos Island, Greece.

Braconi, A., Braga, F., Caprili, S., Gigliotti, R. and Salvatore, W. (2014), "Seismic demand on steel reinforcing bars in reinforced concrete frame structures", Bull. Earthq. Eng., 12(6), 2633-2664.

Braga, F., Gigliotti, R. and Laterza, M. (2006), "Analytical stress-strain relationship for concrete confined by steel stirrups and/or FRP jackets", J. Struct. Eng., 132(9), 1402-1416.

Braga, F., Gigliotti, R., Laterza, M., D'Amato, M. and Kunnath, S. (2012), "Modified steel bar model incorporating bond-slip for seismic assessment of concrete structures", J. Struct. Eng., 138(11), 13421350.

Braga, F., Gigliotti, R., Laterza, M. and D'Amato, M. (2009), "Modellazione non lineare di strutture esistenti in c.a.: confronti con risultati sperimentali", ANIDIS 2009-XIII Convegno ANIDIS " $L$ ' ingegneria Sismica in Italia", Bologna, Italia.

Caprili, S. and Salvatore, W. (2015), "Cyclic behaviour of uncorroded and corroded steel reinforcing bars", Constr. Build. Mater., 76, 168-186.

CEB-FIP Model Code 1990 Design Code (1993), Comitè Euro-International du Beton.

Ciampi, V., Eligenhausen, R., Popov, E.P. and Bertero, V.V. (1983), "Analytical model tor deformed bar bond under generalized excitations", Report EERC 82-23, Earthquake Engineering Research Center, University of California, Berkley.

D. M. Infrastrutture Trasporti 14 gennaio 2008 (2008), Norme Tecniche per le Costruzioni, Italy.

D'Amato, M. (2009), "Analytical models for non linear analysis of RC structures: confined concrete and bond-slip of longitudinal bars", Ph.D. Dissertation, University of Basilicata, Italy.

D'Amato, M., Braga, F., Gigliotti, R., Kunnath, S. and Laterza, M. (2012), "Validation of a modified steel bar model incorporating bond-slip for seismic assessment of concrete structures", J. Struct. Eng., 138(11), 1351-1360.

Dodd, L.L. and Restrepo-Posada, J.I. (1995), "Model for predicting cyclic behavior of reinforcing steel", $J$. Struct. Eng., 121(3), 433-445.

EN 1998-1 (2005), Eurocode 8 - Design of structures for earthquake resistance - Part 1: General rules, seismic actions and rules for buildings.

Fabbrocino, G., Verderame, G.M., Manfredi, G. and Cosenza, E. (2004), "Structural models of critical regions in old-type r.c. frames with smooth rebars", Eng. Struct., 26(14), 2137-2148.

Gigliotti, R. (2002), "RC structures designed for gravity loads: experimental tests on beam-column joints", $\mathrm{Ph} . \mathrm{D}$. Dissertation, University of Salerno and University of Basilicata, Italy.

Gomes, A. and Appleton, J. (1997), "Nonlinear cyclic stress-strain relationship of reinforcing bars including buckling”, Eng. Struct., 19(10), 822-826.

Hakuto, S., Park, R. and Tanaka, H. (1999), "Effect of deterioration of bond of beam bars passing through interior beam-column joints on flexural strength and ductility", ACI Struct. J., 96(S94), 858-864.

Keuser, M. and Mehlhorn, G. (1987), "Finite element models for bond problems", J. Struct. Eng., 113(ST10), 2160-2173.

Limkatanyu, S. and Spacone, E. (2008), "Non linear analysis of reinforced concrete frames including bondslip effects", $14^{\text {th }}$ World Conference on Earthquake Engineering, October 12-17, 2008, Beijing, China.

Lowes, L. and Altoontash, A. (2003), "Modeling reinforced-concrete beam-column joints subjected to cyclic loading", J. Struct. Eng., 129(12), 1686-1697.

Mander, J.B., Priestley, M.J.N. and Park, R. (1984), "Seismic design of bridge piers", Research Report No. 84-2, Department of Civil Engineering, University of Canterbury, New Zealand.

Mazzoni, S., McKenna, F., Scott, M.H. and Fenves, G.L. (2007), OpenSees Command Language Manual, University of California, Berkley, USA.

Menegotto, M. and Pinto, P. (1973), "Method of analysis for cyclically loaded RC plane frames including changes in geometry and non-elastic behavior of elements under combined normal force and bending", Proceedings of Symposium Resistance and Ultimate Deformability of Structures Acted on by WellDefined Repeated Loads, IABSE Reports, 13, 15-22.

Monti, G. and Nuti, C. (1992), "Nonlinear cyclic behaviour of reinforcing bars including buckling", $J$. 
Struct. Eng., 118(12), 3268-3284.

Monti, G., Filippou, F.C. and Spacone, E. (1997), "Finite element for anchored bars under cyclic load reversals", J. Struct. Eng., 123(5), 614-623.

Monti, G., Spacone, E. and Filippou, F.C. (1993), "Model for anchored reinforcing bars under seismic action", Report to the National Science Foundation, University of California, Berkley.

Ngo, D. and Scordelis, A.C. (1969), "Finite element analysis of reinforced concrete beams", J. ACI, 64(3), 153-165.

Panagiotakos, T.B. and Fardis, M.N. (2001), "Deformations of reinforced concrete members at yielding and ultimate", ACI Struct. J., 98(2), 135-148.

Paulay, T. and Priestley, M.N.J. (1992), Seismic Design of Reinforced Concrete and Masonry Buildings, John Wiley \& Sons, Inc., New York.

Bertero, V.V. and Popov, E.P. (1977), "Seismic behavior of ductile moment-resisting reinforced concrete frames. Reinforced concrete structures in seismic zones", SP-53, American Concrete Institute, Detroit.

Rubiano-Benavides, N.R. (1998), "Predictions of the inelastic seismic response of concrete structures including shear deformations and anchorage slip", Ph.D. Dissertation, University of Texas, Austin, USA.

Saatcioglu, M. and Ozcebe, G. (1989), "Response of reinforced concrete columns to simulated seismic loading", ACI Struct. J., 86(1), 3-12.

Tanaka, H. and Park, R. (1990), "Effect of lateral confining reinforcement on the ductile behaviour of reinforced concrete columns", Report 90-2, Department of Civil Engineering, University of Canterbury.

Teran-Gilmore, A. and Jirsa, O. (2007), "Energy demands for seismic design against low-cycle fatigue", Earthq. Eng. Struct., 36(3), 383-404.

Vecchio, F.J. and Collins, M.P. (1986), "The modified compression field theory for reinforced concrete elements subjected to shear", ACI Struct. J., 83(2), 219-231.

Verderame, G.M., Fabbrocino, G., Manfredi, G. and Cosenza, E. (2001), "Analisi sperimentale dell'ancoraggio di barre lisce da cemento armato mediante beam-test", X Congresso Nazionale "L'ingegneria sismica in Italia”, Potenza-Matera. 


\section{Appendix-Analytical formulation of the hardening slip model Basic hypothesis adopted in the formulation}

\section{Slip field}

The slip field $u(x)$ is assumed bi-linear along the bar, with two different branches respectively representing the condition before and after the yielding point. In particular, the slip field $u(x)$ along the bar before yielding (i.e., $\left.\sigma(x) \leq f_{y}\right)$ is then defined by Eq. (H1)

$$
u(x)=\bar{u}_{0}+\frac{x}{L_{0}}\left(u_{L}-\bar{u}_{0}\right)
$$

with

$$
\bar{u}_{0}= \begin{cases}0 & L_{0}<L \\ u_{0} & L_{0}=L\end{cases}
$$

in which $u_{0}$ and $u_{L}$ represent the bar's end displacements, $x$ is the generic abscissa along the bar and $L_{0}$ the portion of the bar involved in relative slip. After yielding the increase of axial stress due to hardening phenomena leads to the corresponding increase of relative slip; the trend of axial slip along the bar is then approximated by two different branches, as presented by Eq. (H3), in which $\bar{u}_{0}$ is defined according to Eq. (H2), $L_{y}$ is the part of the bar in which $u(x) \geq u_{y}, u_{y}$ being the value of displacement corresponding to the yielding strength $f_{y}$. If the axial stress increases, the part of the bar involved in the post-yielding phenomena increases following the trend of $L_{y}$.

$$
u(x)= \begin{cases}\bar{u}_{0}+\frac{u_{y}-\bar{u}_{0}}{L_{0}-L_{y}} \cdot x & \text { for } 0 \leq \mathrm{x} \leq \mathrm{L}_{0}-\mathrm{L}_{\mathrm{y}} \\ u_{y}+\frac{u_{L}-u_{y}}{L_{y}} \cdot\left(x-L_{0}+L_{y}\right) & \text { for } \mathrm{L}_{0}-\mathrm{L}_{\mathrm{y}}<\mathrm{x} \leq \mathrm{L}_{0}\end{cases}
$$

\section{Bond stress-slip relationship}

The bond stress-slip relationship is assumed elastic-perfectly plastic in agreement with the slip model (Gigliotti 2002), following the schematization proposed by Model Code (MC 90) (CEB-IP 1993) and what assumed by Verderame et al. (2001); consequently it is described by Eq. (H4)

$$
\tau(x)= \begin{cases}\frac{\tau_{d}}{u_{1}} \cdot u(x) & \text { if } \mathrm{u}(\mathrm{x}) \leq \mathrm{u}_{1} \\ \tau_{d} & \text { if } \mathrm{u}(\mathrm{x})>\mathrm{u}_{1}\end{cases}
$$

in which $u(x)$ represents the axial slip field along the bar, $\tau_{d}$ is the residual value of bond stress and $u_{1}$ the corresponding slip. 


\section{Stress-strain constitutive law for bars}

The stress-strain constitutive law for steel is assumed elastic-plastic with hardening. The hardening branch is schematized with a linear behaviour up to the point in which the maximum load was reached. The hardening modulus is so defined by Eq. (H5)

$$
E_{h}=\frac{f_{u}-f_{y}}{A_{g t}-\varepsilon_{p}}
$$

in which $f_{u}$ and $f_{y}$ represent the ultimate and yielding strength, $\varepsilon_{p}$ the total deformation at the beginning of the hardening branch and $A_{g t}$ the deformation corresponding to maximum load.

\section{Anchorage at the end of the bar}

The anchorage at the bar end, if present, is represented as a linear function of the displacement corresponding to the end $\left(\bar{u}_{0}\right)$, according to Eq. (H6), in which $k_{h}$ represents the hook stiffness, opportunely determined in relation to the characteristics of the anchorage

$$
F_{h}=k_{h} \cdot \bar{u}_{0}
$$

On the basis of the aforementioned hypotheses, the problem herein presented can be solved in a simple closed form through the use of equilibrium, compatibility and constitutive equations, allowing the determination of an axial stress-slip relationship for the rebar. The application of the equilibrium condition, expressed by Eq. (H7)

$$
\sigma(x)=\frac{F(x)}{A_{b}}=\frac{1}{A_{b}} \int_{0}^{x} \tau(z) \pi D d z+\frac{F_{h}}{A_{b}}
$$

allows the determination of the axial stress field along the bar of diameter $D$ and transversal area $A_{b} . F_{h}$ represents the force acting in correspondence of the hooked end, described as presented by Eq. (H6). Moreover, the use of the compatibility relationships introducing the constitutive equations provides the formulation of relative slip between the two ends of the bar before and after yielding (Eqs. (H8)-(H9), respectively). As visible from Eq. (H9), the two different contributions related to relative slip corresponding to axial stresses lower and higher than yielding are considered, assuming the hardening relationship over a length equal to $L_{y}$

$$
\begin{array}{cr}
\Delta u=u_{L}-u_{0}=\int_{0}^{L} \frac{\sigma(x)}{E_{s}} d x=u_{E}(L) & \sigma(x) \leq f_{y} \\
\Delta u=u_{L}-u_{0}=\int_{0}^{L-L_{y}} \frac{\sigma(x)}{E_{s}} d x+\int_{L-L_{y}}^{L} \varepsilon_{p}+\frac{\sigma(x)-f_{y}}{E_{h}} d x & \sigma(x)>f_{y}
\end{array}
$$




\section{Analytical formulation of possible cases before yielding (adapted from Braga et al. 2012)}

In general terms the bond-slip in correspondence of the free end of the bar can be expressed through compatibility equation

$$
u_{L}=u_{0}+u_{E}(L)
$$

in which $u_{E}$ can be evaluated considering the steel as an elastic material until the yielding strength is reached

$$
u_{E}(L)=\int_{L_{\text {anch }}} \frac{\sigma(x)}{E_{s}} d x
$$

The above presented integral is extended over the anchorage lenght $L_{\text {anch }}$, which could be less than the bar length $L$, (in that case $u_{0}=0$ can be adopted as a valid simplification). If $u_{L} \leq u_{1}$, the adoption of equilibrium and compatibility equations provides stress and elastic displacement along the steel bar, considering $k_{h}^{*}$ as the specific hook stiffness, evaluated as

$$
\begin{gathered}
k_{h}^{*}=\frac{k_{h}}{A_{b}} \\
\sigma(x)=\frac{4}{D} \int_{0}^{x} \tau(x) d x+\frac{F_{h}}{A_{b}}=\frac{4 \tau_{d}}{D u_{1}}\left[u_{0} x+\frac{x^{2}}{2 L}\left(u_{L}-u_{0}\right)\right]+k_{h}^{*} u_{0} \\
u_{E}(x)=\int_{0}^{L} \varepsilon_{E}(x) d x=\frac{1}{E_{s}} \int_{0}^{L} \sigma(x) d x
\end{gathered}
$$

Stress and elastic displacement at the free end are consequently provided by

$$
\begin{gathered}
\sigma_{L}=\frac{2 \tau_{d} L}{D u_{1}}\left(u_{0}+u_{L}\right)+k_{h}^{*} u_{0} \\
u_{E}(L)=u_{L}-u_{0}=\frac{1}{E_{s}}\left[\frac{2 \tau_{d} L^{2}}{3 D u_{1}} \cdot\left(2 u_{0}+u_{L}\right)+k_{h}^{*} u_{0} L\right]
\end{gathered}
$$

If the displacement at the hooked end $\left(u_{0}\right)$ is equal to zero, the anchorage length $L_{0}$ can be expressed as $L_{0}=\sqrt{\frac{3}{2} \frac{E_{s} u_{1}}{\tau_{d}} D}$, that can be also written as $L_{0}=D \sqrt{\frac{3 \pi}{2} \frac{E_{s}}{E_{d}}}$, in which $E_{d}=\frac{\tau_{d}}{u_{1}} \pi D$.

The higher is the value of $E_{d}$, the lower is the bar anchorage $L_{0}$. Consequently, $E_{d}$ can be referred to as "bond stiffness", parameter that quantifies the bond effectiveness between the longitudinal bar and the surrounding concrete. The bar normal stress at the free end is then rewritten in terms of $L_{0}$ as follows

$$
\sigma_{L}\left(u_{L}\right)=\frac{u_{L}}{u_{1}} \sqrt{\frac{6 E_{s} \tau_{d} u_{1}}{D}}=\frac{2 \tau_{d} L_{0}}{D} \cdot \frac{u_{L}}{u_{1}}
$$

If the anchorage length is, on the contrary, higher than $L_{0}$ and relative slip are present for the 
whole length of the bar, the compatibility equation is given by Eq. (Y9), with $u_{0}$ expressed by Eq. (Y10)

$$
\begin{gathered}
u_{L}-u_{0}=\frac{1}{E_{s}}\left[\frac{2 \tau_{d} L^{2}}{3 D u_{1}}\left(2 u_{0}+u_{L}\right)+k_{h}^{*} L u_{0}\right] \\
u_{0}=\frac{3 E_{s} D u_{1}-2 \tau_{d} L^{2}}{3 E_{s} D u_{1}\left(1+\frac{k_{h}^{*} L}{E_{s}}\right)+4 \tau_{d} L^{2}} u_{L}
\end{gathered}
$$

The tensile stress in correspondence of the free end can be evaluated through Eq. (Y11)

$$
\sigma_{L}=\frac{2 \tau_{d} L}{D}\left[\left(1+\frac{D u_{1}}{2 \tau_{d} L} k_{h}^{*}\right) \frac{3 E_{s} D u_{1}-2 \tau_{d} L^{2}}{3 E_{s} D u_{1}\left(1+\frac{k_{h}^{*} L}{E_{s}}\right)+4 \tau_{d} L^{2}}+1\right] \frac{u_{L}}{u_{1}}
$$

If $u_{L}>u_{1}$ the problem can be studied using the following equations

$$
\begin{array}{ll}
\sigma_{E 1}(x)=\frac{4}{D}\left[\int_{0}^{x} \frac{\tau_{d}}{u_{1}} u(z) d z\right]+\frac{F_{h}}{A_{b}} & x \leq x_{1} \\
\sigma_{E 2}(x)=\frac{4}{D}\left[\int_{0}^{x 1} \frac{\tau_{d}}{u_{1}} u(z) d z+\int_{x 1}^{x} \tau_{d} d z\right]+\frac{F_{h}}{A_{b}} & x>x_{1} \\
u_{E 1}(x)=\frac{1}{E_{s}}\left[\int_{0}^{x} \sigma_{E 1}(z) d z\right] & x \leq x_{1} \\
u_{E 2}(x)=\frac{1}{E_{s}}\left[\int_{0}^{x 1} \sigma_{E 1}(z) d z+\int_{x 1}^{x} \sigma_{E 2}(z) d z\right] & x>x_{1}
\end{array}
$$

$x_{1}$ being the portion of the bar where bond slip $u(x)$ is lower than $u_{1}$, given by Eq. (Y16)

$$
\frac{x_{1}}{u_{1}-u_{0}}=\frac{L}{u_{L}-u_{0}} \Rightarrow \frac{x_{1}}{L}=\frac{u_{1}-u_{0}}{u_{L}-u_{0}}
$$

As a consequence, the stress in correspondence of the free end is defined by Eq. (Y17)

$$
\begin{gathered}
\sigma_{L}=\frac{\tau_{d} L\left(2 u_{1} u_{L}-u_{0}{ }^{2}-u_{1}^{2}\right)}{D u_{1}\left(u_{L}-u_{0}\right)}+k_{h}^{*} u_{0} \\
u_{E}(L)=\frac{1}{E_{s}}\left\{\frac{2 \tau_{d} L^{2}\left[u_{1}^{3}+2 u_{0}^{3}+3 u_{1} u_{L}^{2}-3 u_{1}^{2} u_{L}-3 u_{1}^{2} u_{L}\right]}{3 D u_{1}\left(u_{L}-u_{0}\right)^{2}}+k_{h}^{*} L u_{0}\right\}
\end{gathered}
$$

If the anchorage length is lower than $L$, then $u_{0}=0$ and Eq. (Y18) becomes 


$$
u_{L}=\frac{2 \tau_{d} L_{1}^{2}\left(u_{1}^{2}+3 u_{L}^{2}-3 u_{1} u_{L}\right)}{3 E_{s} D u_{L}^{2}}
$$

From Eq. (Y19), the anchorage length $L_{1}$ can be derived

$$
L_{\text {anch }}=\sqrt{\frac{3}{2} \frac{E_{S} D}{\tau_{d}} \frac{u_{L}^{3}}{\left(u_{1}^{2}-3 u_{1} u_{L}+3 u_{L}^{2}\right)}}=L_{0} \sqrt{\frac{u_{L}^{3}}{\left(u_{1}^{2}-3 u_{1} u_{L}+3 u_{L}^{2}\right) u_{1}}}>L_{0}
$$

If $L_{\text {anch }} \leq L$, the expression for the axial stress becomes

$$
\sigma\left(L_{1}\right)=\frac{2 \tau_{d} L_{a n c h}\left(2 u_{L}-u_{1}\right)}{D u_{L}}
$$

On the other hand, if $L_{\text {anch }}>L$, the anchorage length is assumed equal to $L$. In this case, considering Eq. (Y18) and using the Eq. (Y22), the expression Eq. (Y23) can be derived

$$
\begin{gathered}
u_{E}=u_{L}-u_{0} \\
\left(3 E_{s} D u_{1}+4 \tau_{d} L^{2}+3 D u_{1} L k_{h}^{*}\right) u_{0}^{3}-3 u_{L}\left(3 E_{s} D u_{1}+2 \tau_{d} L^{2}+2 D u_{1} L k_{h}^{*}\right) u_{0}^{2}+ \\
+3 D u_{1} u_{L}^{2}\left(3 E_{s}+L k_{h}^{*}\right) u_{0}+u_{1}\left[2 \tau_{d} L^{2}\left(u_{1}^{2}+3 u_{L}^{2}-3 u_{1} u_{L}\right)-3 E_{s} D u^{2}{ }_{1}\right]=0
\end{gathered}
$$

As a consequence, the tensile stress in correspondence of the free end is provided by Eq. (Y17) in which $u_{0}$ is derived from Eq. (Y22). If $u_{0} \geq u_{1}$ a bond strength equal to $\tau_{d}$ is reached over the total bar length $L$ and the bar tensile stress increases thanks to the presence of the end hook, characterized by a linear behaviour until the achievement of yielding strength. In the described case, the following equations can be derived

$$
\begin{gathered}
\sigma_{L}=\frac{4 \tau_{d}}{D} L+k_{h}^{*} u_{1} \\
u_{L}=\frac{2 \tau_{d} L^{2}}{E_{s} D}+\left(\frac{L}{E_{s}} k_{h}^{*}+1\right) u_{0}
\end{gathered}
$$

The equations already presented allow the determination of a stress-slip law for steel reinforcing bar, with reference to different anchorage conditions but not including the postyielding phase for both stress and strain, neglecting hardening phenomena and leading to a not completely correct estimation of the level of strain after yielding on the specimen.

\section{Analytical formulation of possible cases after yielding Case A}

If $u_{0}=0$ (cases A1, A2 and A3 as presented in the core part of the paper), Eq. (3) turns into Eq. (a.1), representing the condition in which only a part of the rebar (indicated as $L_{0}$ ) is directly involved in relative slip 


$$
u(x)= \begin{cases}\frac{u_{y}}{L_{0}-L_{y}} \cdot x & \text { if } 0 \leq \mathrm{x} \leq \mathrm{L}_{0}-\mathrm{L}_{\mathrm{y}} \\ u_{y}+\frac{u_{L}-u_{y}}{L_{y}} \cdot\left(x-L_{0}+L_{y}\right) & \text { if } \mathrm{L}_{0}-\mathrm{L}_{\mathrm{y}}<\mathrm{x} \leq \mathrm{L}_{0}\end{cases}
$$

Moreover, the compatibility equation presented by (9) turns into

$$
u_{L}=\int_{0}^{L_{0}-L_{y}} \frac{\sigma(x)}{E_{s}} d x+\int_{L_{0}-L_{y}}^{L_{0}} \varepsilon_{p}+\frac{\sigma(x)-f_{y}}{E_{h}} d x
$$

The corresponding bond stress-slip law can be directly derived from Eq. (4), providing consequently a bilinear or trilinear relationship depending on the values of $u_{1}$ and $u_{y}$.

Case A1: $u_{y} \leq u_{L} \leq u_{1}$

This case represents the condition in which the force applied in correspondence of the free end of the rebar generates a slip higher than the yielding one $\left(u_{y}\right)$ but lower than the one corresponding to $\tau_{d}$. The bond stress field is defined by two different branches, proportional to the corresponding slip.

The slip field along the rebar is defined by expression (a.1), while the bond stress-slip behaviour along the rebar is consequently defined by

$$
\tau(x)= \begin{cases}\frac{\tau_{d}}{u_{1}} \cdot \frac{u_{y}}{L_{0}-L_{y}} \cdot x & 0 \leq \mathrm{x} \leq \mathrm{L}_{0}-\mathrm{L}_{\mathrm{y}} \\ \frac{\tau_{d}}{u_{1}} \cdot\left[u_{y}+\frac{u_{L}-u_{y}}{L_{y}} \cdot\left(x-L_{0}+L_{y}\right)\right] & \mathrm{L}_{0}-\mathrm{L}_{\mathrm{y}}<\mathrm{x} \leq \mathrm{L}_{0}\end{cases}
$$

The use of equilibrium Eq. (7) allows the determination of the axial stress field along the bar, as presented by

$$
\sigma(x)= \begin{cases}\frac{2 \tau_{d} u_{y}}{D u_{1}\left(L_{0}-L_{y}\right)} x^{2} & 0 \leq \mathrm{x} \leq \mathrm{L}_{0}-\mathrm{L}_{\mathrm{y}} \\ \frac{2 \tau_{d} u_{y}\left(L_{0}-L_{y}\right)}{D u_{1}}+\frac{4 \tau_{d}}{D u_{1}}\left[u_{y}\left(x-L_{0}+L_{y}\right)+\frac{u_{L}-u_{y}}{2 L_{y}} \cdot\left(x-L_{0}+L_{y}\right)^{2}\right] & \mathrm{L}_{0}-\mathrm{L}_{\mathrm{y}}<\mathrm{x} \leq \mathrm{L}_{0}\end{cases}
$$

Taking into account the equilibrium condition along the bar, the portion of the bar in which axial stresses are lower than yielding strength $\left(L_{0}-L_{y}\right)$ Os determined. The value $L_{0}-L_{y}$, defined according to equation

$$
\int_{L_{0}-L_{y}}^{L_{0}} \pi D \tau(x) d x=\frac{\pi D^{2}}{4} \cdot\left(\sigma\left(L_{0}\right)-f_{y}\right) \Rightarrow L_{0}-L_{y}=\frac{D \cdot f_{y} \cdot u_{1}}{2 \cdot \tau_{d} \cdot u_{y}}
$$

remains constant until the total length of the bar is not involved in relative slip.

The slip in correspondence of the free end of the rebar $\left(u_{L}\right)$, in the case of $u_{0}=0$ and consequently for $\Delta u=u_{L}$, is expressed by Eq. (a.2), turning in this case into 


$$
\begin{aligned}
& \Delta u=\int_{0}^{L_{0}-L_{y}} \frac{\sigma(x)}{E_{s}} d x+\int_{L_{0}-L_{y}}^{L_{0}} \varepsilon_{p}+\frac{\sigma(x)-f_{y}}{E_{h}} d x= \\
& -\frac{f_{y} L_{y}}{E_{h}}+L_{y} \varepsilon_{p}+\frac{2 \tau_{d} u_{L} L_{y}{ }^{2}}{3 D \cdot E_{h} u_{1}}+\frac{2\left(L_{0}-L_{y}\right)^{2} u_{y} \tau_{d}}{3 D \cdot u_{1}}+\frac{2 L_{0} L_{y} u_{y} \tau_{d}}{D \cdot E_{h} u_{1}}-\frac{2 L_{y}^{2} u_{y} \tau_{d}}{3 D \cdot E_{h} u_{1}}=u_{L}
\end{aligned}
$$

The boundary condition for case "A1" is reached when $u_{L}=u_{1}$. The axial stress in correspondence of the free end is provided by

$$
\sigma_{L 0}=\frac{2 \tau_{d}\left(L_{y} u_{L}+L_{0} u_{y}\right)}{D u_{1}} \Rightarrow \sigma_{L 0\left(u_{L}=u_{1}\right)}=\frac{2 \tau_{d}\left(L_{y} u_{1}+L_{0} u_{y}\right)}{D u_{1}}
$$

Case A2: $u_{y}<u_{1}<u_{L}$

If $u_{1}>u_{y}$ the bond stress field presented by Eq. (4) is described by three different branches, two of them proportional to the corresponding slip and the last one constant and equal to $\tau_{d}$ (Fig. 7) as presented by

$$
\tau(x)= \begin{cases}\frac{\tau_{d}}{u_{1}} \cdot \frac{u_{y}}{L_{0}-L_{y}} \cdot x & 0 \leq \mathrm{x} \leq \mathrm{L}_{0}-\mathrm{L}_{\mathrm{y}} \\ \frac{\tau_{d}}{u_{1}} \cdot\left[u_{y}+\frac{u_{L}-u_{y}}{L_{y}} \cdot\left(x-L_{0}+L_{y}\right)\right] & \mathrm{L}_{0}-\mathrm{L}_{\mathrm{y}}<\mathrm{x} \leq \mathrm{x}_{1} \\ \tau_{d} & \mathrm{x}_{1}<\mathrm{x} \leq \mathrm{L}_{0}\end{cases}
$$

In which $x_{1}$ represents the abscissa along the rebar in which the bond stress is equal to $\tau_{d}$ (and consequently $u(x)=u_{1}$ ), according to the following equation

$$
x_{1}=L_{0}+L_{y} \cdot \frac{u_{1}-u_{L}}{u_{L}-u_{y}} \geq L_{0}-L_{y}
$$

The use of equilibrium Eq. (7) allows the evaluation of the axial stress field along the bar, as presented by

$$
\sigma(x)= \begin{cases}\frac{2 \tau_{d} u_{y}}{D \cdot u_{1} \cdot\left(L_{0}-L_{y}\right)} \cdot x^{2} & 0 \leq \mathrm{x} \leq \mathrm{L}_{0}-\mathrm{L}_{\mathrm{y}} \\ \frac{2 \tau_{d} u_{y}\left(L_{0}-L_{y}\right)}{D \cdot u_{1}}+\frac{4 \cdot \tau_{d}}{D \cdot u_{1}}\left[u_{y}\left(x-L_{0}+L_{y}\right)+\frac{u_{L}-u_{y}}{2 L_{y}}\left(L_{y}-L_{0}+x\right)^{2}\right] & \mathrm{L}_{0}-\mathrm{L}_{\mathrm{y}}<\mathrm{x} \leq \mathrm{x}_{1} \\ \frac{2 \tau_{d} u_{y}\left(L_{0}-L_{y}\right)}{D \cdot u_{1}}+\frac{2 \tau_{d} L_{y}\left(u^{2}{ }_{1}-u^{2}{ }_{y}\right)}{D \cdot u_{1} \cdot\left(u_{L}-u_{y}\right)}+\frac{4 \cdot \tau_{d}}{D \cdot u_{1}}\left(x-x_{1}\right) & \mathrm{x}_{1}<\mathrm{x} \leq \mathrm{L}_{0}\end{cases}
$$

Through the use of the equilibrium condition along the bar (Fig. 9), the portion of the bar in which axial stresses are lower than yielding strength $\left(L_{0}-L_{y}\right)$ is determined 


$$
\begin{gathered}
\int_{L_{0}-L_{y}}^{L_{0}} \pi D \tau(x) d x=\frac{\pi D^{2}}{4} \cdot\left(\sigma\left(L_{0}\right)-f_{y}\right) \Rightarrow \pi D \int_{0}^{x_{1}} \frac{\tau_{d}}{u_{1}} \cdot \frac{u_{L}-u_{y}}{L_{y}} \cdot\left(x-L_{0}+L_{y}\right) d x+\int_{x_{1}}^{L_{0}} \pi D \tau_{d} d x=\frac{\pi D^{2}}{4} \cdot\left(\sigma\left(L_{0}\right)-f_{y}\right) \\
\Rightarrow L_{0}-L_{y}=\frac{D \cdot f_{y} \cdot u_{1}}{2 \tau_{d} \cdot u_{y}}
\end{gathered}
$$

The formulation is the same of case "A1". The slip in correspondence of the free end of the bar $\left(u_{L}\right)$ is expressed by Eq. (a.1), turning in this case into

$$
\begin{gathered}
\Delta u=\int_{0}^{L_{0}-L_{y}} \frac{\sigma(x)}{E_{s}} d x+\int_{L_{0}-L_{y}}^{x_{1}} \varepsilon_{p}+\frac{\sigma(x)-f_{y}}{E_{h}} d x+\int_{x_{1 y}}^{L_{0}} \varepsilon_{p}+\frac{\sigma(x)-f_{y}}{E_{h}} d x=\frac{2 \tau_{d} \cdot u_{y} \cdot\left(L_{0}-L_{y}\right)^{2}}{3 D \cdot E_{s} \cdot u_{1}}+ \\
L_{y}\left(\begin{array}{l}
-3 D u_{1} \cdot\left(u_{L}-u_{y}\right)^{2} \cdot\left(f_{y}-E_{h} \cdot \varepsilon_{p}\right)+2 \tau_{d} \cdot\left(3 L_{0} u_{y}\left(u_{L}-u_{y}\right)^{2}+\right. \\
+L_{y} \cdot\left(u_{1}-u_{y}\right) \cdot\left(u_{1}{ }^{2}-3 u_{1} u_{L}+3 u_{L}{ }^{2}+u_{1} u_{y}-3 u_{y} u_{L}+u_{y}{ }^{2}\right)
\end{array}\right) \cdot \frac{1}{3 D E_{h} u_{1} \cdot\left(u_{L}-u_{y}\right)^{2}}
\end{gathered}
$$

Eq. (22), moreover, provides the axial stress in correspondence of the free end of the bar

$$
\sigma_{L 0}=-\frac{2 \tau_{d} \cdot\left(L_{y} \cdot\left(u_{1}^{2}-2 u_{1} u_{L}+u_{y} u_{L}\right)-\left(u_{L}-u_{y}\right) \cdot\left(2 L_{0} u_{y}+L_{0} \cdot\left(-2 u_{1}+u_{y}\right)\right)\right)}{D u_{y}}
$$

Case A3: $u_{1}<u_{y}<u_{L}$

The slip field along the rebar is defined by Eq. (a.1). Being $u_{y}>u_{1}$ the bond stress field is described by two different branches, respectively proportional to the corresponding slip and constant and equal to $\tau_{d}$ (Fig. 7), as presented by

$$
\tau(x)= \begin{cases}\frac{\tau_{d}}{u_{1}} \cdot \frac{u_{y}}{L_{0}-L_{y}} \cdot x & 0 \leq \mathrm{x} \leq x_{1} \\ \tau_{d} & \mathrm{x}_{1}<\mathrm{x} \leq \mathrm{L}_{0}\end{cases}
$$

Moreover, the axial stress field, derived through the application of equilibrium equations, is presented by

$$
\sigma(x)= \begin{cases}\frac{2 \tau_{d} u_{y}}{D u_{1} \cdot\left(L_{0}-L_{y}\right)} x^{2} & 0 \leq \mathrm{x} \leq x_{1} \\ \frac{2 \tau_{d} u_{y} \cdot x_{1}^{2}}{D u_{1} \cdot\left(L_{0}-L_{y}\right)}+\frac{4 \tau_{d}}{D} \cdot\left(x-x_{1}\right) & x_{1}<\mathrm{x} \leq \mathrm{L}_{0}\end{cases}
$$

On the base of previous considerations $L_{0}-L_{y}$ can be evaluated through the use of Eq. (a.14) turning in this case into

$$
\int_{L_{0}-L_{y}}^{L_{0}} \pi D \tau(x) d x=\frac{\pi D^{2}}{4}\left(\sigma\left(L_{0}\right)-f_{y}\right) \Rightarrow L_{0}-L_{y}=\frac{D f_{y} u_{y}}{2 \tau_{d}\left(2 u_{y}-u_{1}\right)}
$$


The slip in correspondence of the free end of the rebar $\left(u_{L}\right)$ for $\Delta u=u_{L}$ is expressed by

$$
\begin{aligned}
& \Delta u=\int_{0}^{x_{1}} \frac{\sigma(x)}{E_{s}} d x+\int_{x_{1}}^{L_{0}-L_{y}} \frac{\sigma(x)}{E_{s}} d x+\int_{L_{0}-L_{y}}^{L_{0}} \varepsilon_{p}+\frac{\sigma(x)-f_{y}}{E_{h}} d x= \\
& =\int_{0}^{x_{1}} \frac{1}{E_{s}} \frac{2 \tau_{d} u_{y}}{D u_{1}\left(L_{0}-L_{y}\right)} x^{2} d x+\int_{x_{1}}^{L_{0}-L_{y}} \frac{1 \cdot}{E_{s}}\left(\frac{2 \tau_{d} u_{y} \cdot x_{1}^{2}}{D u_{1} \cdot\left(L_{0}-L_{y}\right)}+\frac{4 \tau_{d}}{D} \cdot\left(x-x_{1}\right)\right) d x+ \\
& +\int_{L_{0}-L_{y}}^{L_{0}} \varepsilon_{p}+\frac{\left(\frac{2 \tau_{d} u_{y} \cdot x_{1}^{2}}{D u_{1} \cdot\left(L_{0}-L_{y}\right)}+\frac{4 \tau_{d}}{D} \cdot\left(x-x_{1}\right)\right)-f_{y}}{E_{h}} d x=\frac{-3 D E_{s} L_{y} u_{y}^{2} \cdot\left(f_{y}-E_{h} \varepsilon_{p}\right)}{3 D E_{h} E_{s} u_{y}^{2}}+ \\
& +\frac{\left.2\left(E_{h}\left(L_{0}-L_{y}\right)^{2}\left(u_{1}-3 u_{1} u_{y}+3 u_{y}{ }^{2}\right)-3 E_{s} L_{y} u_{y}\left(L_{0}\left(u_{1}-2 u_{y}\right)+L_{y}\left(-u_{1}+u_{y}\right)\right)\right) \tau_{d}\right)}{3 D E_{h} E_{s} u_{y}^{2}}
\end{aligned}
$$

Finally, the axial stress in correspondence of the free end of the bar is provided

$$
\sigma_{L 0}=\frac{2 \tau_{d}\left(L_{y} u_{1}+2 L_{0} u_{y}-L_{0} u_{1}\right)}{D u_{y}}
$$

\section{Case B}

The general condition in which the slip in correspondence of the end bar is not equal to zero and yielding strength is overpassed can be described by cases indicated by "B", as presented in the Fig. 8. The slip field is defined by Eq. (9) and bond and axial stress can be derived using equilibrium conditions. In these cases, the total length of the rebar $L$ is directly involved in relative slip. The force acting in correspondence of the hooked end, defined according to Eq. (6), can be described also by

$$
k_{h}^{*}=\frac{k_{h}}{A_{b}}
$$

in which $k_{h}^{*}$ represents the specific hook stiffness defined as the ratio between the hooked end stiffness and the bar area (D'Amato et al. 2012)

Case B1: $u_{y} \leq u_{L} \leq u_{1}, u_{0} \neq 0$

This case refers to the condition in which the force applied in correspondence of the free end of the specimen generates a slip higher than the yielding one $\left(u_{y}\right)$ but lower than the one corresponding to $\tau_{d}$. The bond stress field is defined by two different branches, proportional to the corresponding slip (Fig. 8)

$$
\tau(x)= \begin{cases}\frac{\tau_{d}}{u_{1}} \cdot\left[u_{0}+\frac{u_{y}-u_{0}}{L-L_{y}} \cdot x\right] & 0 \leq \mathrm{x} \leq \mathrm{L}-\mathrm{L}_{\mathrm{y}} \\ \frac{\tau_{d}}{u_{1}} \cdot\left[u_{y}+\frac{u_{L}-u_{y}}{L_{y}} \cdot\left(x-L+L_{y}\right)\right] & \mathrm{L}-\mathrm{L}_{\mathrm{y}}<\mathrm{x} \leq \mathrm{L}\end{cases}
$$


The axial stress field, obtained using equilibrium equation, is given by

$$
\sigma(x)= \begin{cases}\frac{4 \tau_{d}}{D u_{1}} \cdot\left(u_{0} x+\frac{u_{y}-u_{0}}{L-L_{y}} \cdot \frac{x^{2}}{2}\right)+k_{h}^{*} \cdot u_{0} & 0 \leq \mathrm{x} \leq \mathrm{L}-\mathrm{L}_{\mathrm{y}} \\ \frac{4 \tau_{d}}{D u_{1}} \cdot\left(u_{y}\left(x-L+L_{y}\right)+\frac{\left(u_{L}-u_{y}\right) \cdot\left(x-L+L_{y}\right)^{2}}{2 L_{y}}\right)+\frac{2 \tau_{d}}{D u_{1}}\left(L-L_{y}\right) \cdot\left(u_{0}+u_{y}\right) \cdot k_{h}^{*} \cdot u_{0} & \mathrm{~L}-\mathrm{L}_{\mathrm{y}}<\mathrm{x} \leq \mathrm{L}\end{cases}
$$

Taking into account the equilibrium condition along the bar, the portion of the bar in which axial stresses are lower than yielding strength $\left(L-L_{y}\right)$ can be evaluated

$$
\begin{gathered}
\int_{L-L_{y}}^{L} \pi D \tau(x) d x=\frac{\pi D^{2}}{4}\left(\sigma(L)-f_{y}\right) \Rightarrow \int_{L-L_{y}}^{L} \pi D \cdot \frac{\tau_{d}}{u_{1}} \cdot\left[u_{y}+\frac{u_{L}-u_{y}}{L_{y}} \cdot\left(x-L+L_{y}\right)\right] d x=\frac{\pi D^{2}}{4}\left(\sigma(L)-f_{y}\right) \\
\Rightarrow L-L_{y}=\frac{D\left(f_{y} u_{1}-k_{h}^{*} u_{0} u_{1}\right)}{2 \tau_{d}\left(u_{y}+u_{0}\right)}
\end{gathered}
$$

The relative slip between the two ends of the steel rebar $(\Delta u)$ are expressed through Eq. (9), turning in this case into the following expression

$$
\begin{aligned}
& \Delta u=\int_{0}^{L-L_{y}} \frac{\sigma(x)}{E_{s}} d x+\int_{L-L_{y}}^{L} \varepsilon_{p}+\frac{\sigma(x)-f_{y}}{E_{h}} d x=\frac{2 \tau_{d}}{3 D E_{s} u_{1}} \cdot\left(L-L_{y}\right)^{2} \cdot\left(2 u_{0}+u_{y}\right)+ \\
& \frac{\left(L-L_{y}\right) \cdot k_{h}^{*} u_{0}}{E_{S}}+L_{y} \cdot\left(\varepsilon_{p}-\frac{f_{y}}{E_{h}}+\frac{k_{h}^{*} u_{0}}{E_{h}}\right)+\frac{2 \tau_{d} L_{y}}{3 D E_{h} u_{1}} \cdot\left(L y \cdot\left(u_{L}-u_{y}-3 u_{0}\right)+3 L \cdot\left(u_{0}+u_{y}\right)\right)=u_{L}-u_{0}
\end{aligned}
$$

Finally, Eq. (B6) provides the axial stress at the free end

$$
\sigma_{L}=k_{h}^{*} \cdot u_{0}+2 \tau_{d} \cdot \frac{L_{y}\left(-u_{0}+u_{L}\right)+L\left(u_{0}+u_{y}\right)}{D u_{1}}
$$

Case B2: $u_{y}<u_{1} \leq u_{L}, u_{0} \neq 0$

If $u_{1}>u_{y}$ the bond stress field is defined by three different branches, two of them proportional to the corresponding slip, and the last one constant and equal to $\tau_{d}$, as presented by

$$
\tau(x)= \begin{cases}\frac{\tau_{d}}{u_{1}} \cdot\left[u_{0}+\frac{u_{y}-u_{0}}{L-L_{y}} \cdot x\right] & 0 \leq \mathrm{x} \leq \mathrm{L}-\mathrm{L}_{\mathrm{y}} \\ \frac{\tau_{d}}{u_{1}} \cdot\left[u_{y}+\frac{u_{L}-u_{y}}{L_{y}} \cdot\left(x-L+L_{y}\right)\right] & \mathrm{L}-\mathrm{L}_{\mathrm{y}}<\mathrm{x} \leq \mathrm{x}_{1} \\ \tau_{d} & \mathrm{x}_{1}<\mathrm{x} \leq \mathrm{L}\end{cases}
$$

The total length of the rebar $L$ is involved in relative slip and $x_{1}$ represented the abscissa in which the bond stress reaches $\tau_{d}$ (and consequently $u(x)=u_{1}$ ). The use of equilibrium equation allows the determination of the axial stress field along the bar 


$$
\sigma(x)= \begin{cases}\frac{4 \tau_{d}}{D u_{1}}\left(u_{0} x+\frac{u_{y}-u_{0}}{L-L_{y}} \cdot \frac{x^{2}}{2}\right)+k_{h}^{*} u_{0} & 0 \leq \mathrm{x} \leq \mathrm{L}-\mathrm{L}_{\mathrm{y}} \\ \frac{2 \tau_{d}}{D u_{1}}\left(L-L_{y}\right) \cdot\left(u_{0}+u_{y}\right)+k_{h}^{*} u_{0}+\frac{4 \tau_{d}}{D u_{1}} \cdot\left(u_{y}\left(x-L+L_{y}\right)+\frac{\left(u_{L}-u_{y}\right) \cdot\left(x-L+L_{y}\right)^{2}}{2 L_{y}}\right) & \mathrm{L}-\mathrm{L}_{\mathrm{y}}<\mathrm{x} \leq x_{1} \\ \frac{4 \tau_{d}}{D}\left(x-x_{1}\right)+2 \tau_{d} \cdot \frac{L\left(u_{L}-u_{y}\right)\left(u_{0}+u_{y}\right)+L_{y}\left(u_{1}^{2}-u_{0} u_{L}+u_{0} u_{y}-u_{L} u_{y}\right)}{D u_{1} \cdot\left(u_{L}-u_{y}\right)}+k_{h}^{*} u_{0} & \mathrm{x}_{1}<\mathrm{x} \leq \mathrm{L}\end{cases}
$$

Taking into account the equilibrium condition (Fig. 9), the portion of the bar in which axial stresses are lower than the yielding strength $\left(L-L_{y}\right)$ can be determined

$$
\begin{gathered}
\int_{L-L_{y}}^{L} \pi D \tau(x) d x=\frac{\pi D^{2}}{4}\left(\sigma(L)-f_{y}\right) \Rightarrow \int_{L-L_{y}}^{x_{1}} \pi D \frac{\tau_{d}}{u_{1}} \cdot\left[u_{y}+\frac{u_{L}-u_{y}}{L_{y}} \cdot\left(x-L+L_{y}\right)\right] d x+\int_{x_{1}}^{L} \pi D \tau_{d} d x=\frac{\pi D^{2}}{4} \cdot\left(\sigma(L)-f_{y}\right) \\
\Rightarrow L-L_{y}=\frac{D f_{y} u_{1}}{2 \tau_{d} \cdot\left(u_{0}+u_{y}\right)}-\frac{D k_{h}^{*} \cdot u_{0} u_{1}}{2 \tau_{d} \cdot\left(u_{0}+u_{y}\right)}
\end{gathered}
$$

The relative slip between the two ends of the rebar $(\Delta u)$ are expressed by

$$
\begin{aligned}
& \Delta u=\int_{0}^{L-L_{y}} \frac{\sigma(x)}{E_{s}} d x+\int_{L-L_{y}}^{x_{1}} \varepsilon_{p}+\frac{\sigma(x)-f_{y}}{E_{h}} d x+\int_{x 1}^{L} \varepsilon_{p}+\frac{\sigma(x)-f_{y}}{E_{h}} d x=\frac{2 \tau_{d}\left(L-L_{y}\right)^{2}\left(2 u_{0}+u_{y}\right)}{3 D E_{s} u_{1}}+ \\
& +\frac{L_{y}}{3 D E_{h} u_{1}\left(u_{L}-u_{y}\right)^{2}} \cdot\left(\begin{array}{l}
-3 D u_{1}\left(u_{L}-u_{y}\right)^{2}\left(f_{y}-E_{h} \varepsilon_{p}\right)+2 \tau_{d}\left(3 L\left(u_{L}-u_{y}\right)^{2}\left(u_{0}+u_{y}\right)+\right. \\
+L_{y}\left(u_{1}^{3}-3 u_{1}{ }^{2} u_{L}+3 u_{1} u_{L}{ }^{2}-3 u_{0}\left(u_{L}-u_{y}\right)^{2}-u_{y}\left(3 u_{L}^{2}-3 u_{L} u_{y}+u_{y}^{2}\right)\right)
\end{array}\right)+ \\
& +k_{h}^{*} u_{0} \cdot\left(\frac{L-L_{y}}{E_{s}}+\frac{L_{y}}{E_{h}}\right)=u_{L}-u_{0}
\end{aligned}
$$

Eq. (b.11) provides the formula for the evaluation of the axial stress at the free end

$$
\sigma_{L}=-2 \tau_{d} \cdot \frac{L_{y}\left(u_{1}^{2}+u_{0} u_{L}-2 u_{1} u_{L}-u_{0} u_{y}+u_{y} u_{L}\right)-L\left(u_{L}-u_{y}\right) \cdot\left(u_{0}+u_{y}\right)}{D u_{y} \cdot\left(u_{L}-u_{y}\right)}+k_{h}^{*} u_{0}
$$

Case B3: $u_{1}<u_{\mathrm{y}} \leq u_{L}, u_{0} \neq 0$

If $u_{y}>u_{1}$ the bond stress field is defined by two different branches, proportional to the corresponding slip, as presented by

$$
\tau(x)= \begin{cases}\frac{\tau_{d}}{u_{1}} \cdot\left[u_{0}+\frac{u_{y}-u_{0}}{L-L_{y}} \cdot x\right] & \text { if } 0 \leq \mathrm{x} \leq \mathrm{x}_{1} \\ \tau_{d} & \text { if } \mathrm{x}_{1}<\mathrm{x} \leq \mathrm{L}\end{cases}
$$

The axial stress field is consequently derived through the application of equilibrium equations

$$
\sigma(x)= \begin{cases}\frac{4 \tau_{d}}{D u_{1}} \cdot\left(u_{0} x+\frac{u_{y}-u_{0}}{L-L_{y}} \cdot \frac{x^{2}}{2}\right)+k_{h}^{*} u_{0} & 0 \leq \mathrm{x} \leq \mathrm{x}_{1} \\ \frac{4 \tau_{d}}{D} \cdot\left(x-x_{1}\right)+k_{h}^{*} u_{0}+\frac{2 \tau_{d}}{D u_{1}} \cdot\left(L-L_{y}\right) \cdot\left(\frac{u_{1}^{2}-u_{0}^{2}}{u_{y}-u_{0}}\right) & \mathrm{x}_{1}<\mathrm{x} \leq \mathrm{L}\end{cases}
$$


Taking into account the equilibrium condition along the bar (Fig. 9), the portion of the bar in which axial stresses are lower than yielding strength $\left(L-L_{y}\right)$ can be evaluated

$$
\begin{aligned}
& \int_{L-L_{y}}^{L} \pi D \tau(x) d x=\frac{\pi D^{2}}{4} \cdot\left(\sigma(L)-f_{y}\right) \Rightarrow \int_{L-L_{y}}^{L} \pi D \tau_{d} d x=\frac{\pi D^{2}}{4} \cdot\left(\sigma(L)-f_{y}\right) \\
& \Rightarrow L-L_{y}=\frac{D u_{1} \cdot\left(-u_{y}+u_{0}\right) \cdot\left(f_{y}-k_{h}^{*} u_{0}\right)}{2 \tau_{d} \cdot\left(u_{0}{ }^{2}+u_{1}{ }^{2}-2 u_{y} u_{1}\right)}
\end{aligned}
$$

The relative slip between the two ends of the steel rebar $(\Delta u)$ are expressed through Eq. 9, turning, in this case into

$$
\begin{aligned}
& \Delta u=\int_{0}^{x_{1}} \frac{\sigma(x)}{E_{s}} d x+\int_{x_{1}}^{L-L_{y}} \frac{\sigma(x)}{E_{s}} d x+\int_{L-L_{y}}^{L} \varepsilon_{p}+\frac{\sigma(x)-f_{y}}{E_{h}} d x=k_{h}^{*} u_{0} \cdot\left(\frac{L-L_{y}}{E_{s}}+\frac{L_{y}}{E_{h}}\right)+ \\
& +\frac{2 \tau_{d} \cdot\left(L-L_{y}\right)^{2}\left(u_{0}-u_{1}\right)^{2}\left(2 u_{0}+u_{1}\right)}{3 D E_{s} u_{1} \cdot\left(u_{0}-u_{y}\right)^{2}}+\frac{2 \tau_{d} \cdot\left(L-L_{y}\right)^{2}\left(u_{1}-u_{y}\right) \cdot\left(u_{0}{ }^{2}-u_{y} u_{1}\right)}{3 D E_{s} u_{1} \cdot\left(u_{0}-u_{y}\right)^{2}}+ \\
& +\frac{L_{y} \tau_{d} \cdot\left(-D u_{1} \cdot\left(u_{0}-u_{y}\right) \cdot\left(f_{y}-E_{h} \varepsilon_{p}\right)\right)}{D E_{h} u_{1} \cdot\left(u_{0}-u_{y}\right)}+\frac{2 L_{y} \tau_{d} \cdot\left(L \cdot\left(u_{0}^{2}+u_{1}^{2}-2 u_{1} u_{y}\right)-L_{y} \cdot\left(u_{0}^{2}+u_{1}^{2}-u_{1} u_{y}-u_{1} u_{0}\right)\right)}{D E_{h} u_{1} \cdot\left(u_{0}-u_{y}\right)}= \\
& =u_{L}-u_{0}
\end{aligned}
$$

Moreover, Eq. (b.16) provides the axial stress in correspondence of the free end

$$
\sigma_{L}=2 \tau_{d} \cdot \frac{-L_{y} \cdot\left(u_{0}-u_{1}\right)^{2}+L \cdot\left(u_{0}^{2}-2 u_{1} u_{y}+u_{1}^{2}\right)}{D u_{1}\left(u_{0}-u_{y}\right)}+k_{h}^{*} \cdot u_{0}
$$

